Amenorrhoea

Absence or cessation of

menstruation.

Menstrual health A state of complete physical, mental, and social well-being and not merely the absence of disease or infirmity, in relation to the menstrual cycle.
MRC Centre for Reproductive Health, University of Edinburgh, Edinburgh, UK. 凶e-mail: hilary.critchley@ ed.ac.uk

\title{
Uterine bleeding: how understanding endometrial physiology underpins menstrual health
}

Varsha Jain, Rohan R. Chodankar, Jacqueline A. Maybin (1D and Hilary O. D. Critchley $\mathbb{D}^{凶}$

Abstract | Menstruation is a physiological process that is typically uncomplicated. However, up to one third of women globally will be affected by abnormal uterine bleeding (AUB) at some point in their reproductive years. Menstruation (that is, endometrial shedding) is a fine balance between proliferation, decidualization, inflammation, hypoxia, apoptosis, haemostasis, vasoconstriction and, finally, repair and regeneration. An imbalance in any one of these processes can lead to the abnormal endometrial phenotype of AUB. Poor menstrual health has a negative impact on a person's physical, mental, social, emotional and financial well-being. On a global scale, iron deficiency and iron deficiency anaemia are closely linked with AUB, and are often under-reported and under-recognized. The International Federation of Gynecology and Obstetrics have produced standardized terminology and a classification system for the causes of AUB. This standardization will facilitate future research endeavours, diagnosis and clinical management. In a field where no new medications have been developed for over 20 years, emerging technologies are paving the way for a deeper understanding of the biology of the endometrium in health and disease, as well as opening up novel diagnostic and management avenues.

Menstruation is defined as "a woman's monthly bleeding from the reproductive (vaginal) tract, as a consequence of cyclical changes in hormonal activity"'. Menstruation is a physiological process that, for most women, is a routine part of life. However, menstrual abnormalities are estimated to affect up to one third of women globally and can have a debilitating impact on an individual's quality of life ${ }^{1-3}$. Menstrual abnormalities have become increasingly prominent in the latter half of the 20th century, probably due to increased prevalence and recognition ${ }^{4}$. However, menstrual complaints remain under-reported ${ }^{4}$.

Currently, women living in high-income countries, for example, the USA or UK, are estimated to have approximately $400-450$ ovulations in their lifetime. This estimate is based on the average age at menarche (12.5 years), average age at menopause ( 50.5 years), age at first birth (29 years), number of children conceived per lifetime (1.8 children per woman) and the average duration of breastfeeding (4 months) $)^{5,6}$. In contrast to these figures, research estimates that hunter-gatherer women of the Palaeolithic era experienced approximately 160 ovulations per lifetime, due to later average age at menarche (16 years) and earlier menopause (47 years). Additionally, women from this era had their first child at an earlier age (19 years), conceived more children over their lifetime (six children on average) and breastfed for much longer (2-3 years per child) than women living now $^{5}$. A previous study estimated that women in the Palaeolithic era had no more than 40 ovulations per lifetime based on different populations, with different family sizes and length of lactational amenorrhoea ${ }^{7}$.

In this Review, we define typical menstruation using a standardized system developed by global experts and approved by the International Federation of Gynecology and Obstetrics (FIGO) Menstrual Disorders Committee (MDC). This system facilitates the definition and standardization of what constitutes abnormal uterine bleeding (AUB: FIGO Systems 1 and 2)2. We address the considerable impact of non-malignant AUB across the globe before discussing how delineating the physiology of menstruation could inform and improve the management of non-malignant AUB by optimizing diagnosis and treatment. This Review focuses on the biomedical aspects of menstruation, while acknowledging that cultural, social, environmental and political factors have a notable influence on menstrual health ${ }^{8}$. Comprehensive discussion of these important non-biomedical aspects can be found elsewhere and are therefore not discussed in detail here?. 


\section{Key points \\ - Menstruation is a phenomenon of repeated tissue injury and repair that is a fine balance between proliferation, decidualization, inflammation, hypoxia, apoptosis, haemostasis, vasoconstriction and, finally, repair and regeneration. \\ - The endometrium is a dynamic, multicellular tissue highly responsive to sex steroids; subtle variances in the endometrial environment and, therefore, functioning, can lead to abnormal uterine bleeding (AUB). \\ - $A U B$ is a debilitating symptom that affects up to one third of reproductive-aged women; comprehensive knowledge of menstrual cycle physiology is crucial for understanding and progressing endometrial physiology research. \\ - There is a high prevalence of iron deficiency and iron deficiency anaemia in those with $A U B$, on a global scale, and this is often under-recognized and under-reported. \\ - The terminology and definitions for diagnosing causes of AUB are now standardized in the International Federation of Gynecology and Obstetrics Systems 1 and 2, and should be followed for ease of clinical and research synchrony. \\ - Treatments for AUB are not specific and a third of patients resort to a hysterectomy for resolution of symptoms, highlighting a clinically unmet need for more targeted and personalized treatments.}

\section{Polyp}

A growth or mass protruding

from a mucous membrane

Adenomyosis

A benign invasion of

the myometrium by the

endometrium.

Leiomyoma

A usually benign tumour

arising from smooth muscle

cells of the uterus; $<1 \%$ of

leiomyomas are malignant.

Coagulopathy

A disorder of blood coagulation.

Ovulatory dysfunction

Abnormal, irregular or absent

ovulation.

latrogenic

Resulting from the activity

of a health-care provider or institution.

\section{Abnormal uterine bleeding}

Menstrual bleeding should be assessed using six parameters: frequency, duration, regularity, volume, the presence or absence of intermenstrual bleeding and unscheduled bleeding (in those individuals receiving progestin with or without oestrogen $)^{2,10}$. Typical physiological menstruation occurs every 24-38 days, lasts less than 8 days and has a longest to shortest cycle variation cal menstrual bleeding should not interfere with quality of life. AUB is the widely accepted umbrella term for menstrual abnormalities and is subdivided into either of less than 7-9 days. Additionally, the volume of typi- acute or chronic ${ }^{2,10}$. Chronic AUB is "bleeding from the uterine corpus that is abnormal in volume, regularity, and/or timing, and has been present for the majority of the past 6 months" ${ }^{10}$. Acute AUB is "an episode of heavy bleeding that, in the opinion of the clinician, is of sufficient quantity to require immediate intervention to prevent further blood loss"10. Acute AUB can occur in the presence of chronic AUB or as an independent episode. AUB can be frequent or infrequent, prolonged, irregular or heavy. Heavy menstrual bleeding (HMB) is defined as "excessive menstrual blood loss which interferes with a woman's physical, social, emotional and/or material quality of life"11. Intermenstrual bleeding is the spontaneous bleeding occurring between menstrual cycles that can be either cyclical or random ${ }^{10}$. This Review focuses on the biomedical aspects of conditions that lead to HMB.

\section{Classification of AUB: PALM-COEIN}

In 2011, the FIGO MDC set out the core classification of conditions that cause AUB, with minor updates in $2018\left(\mathrm{REFS}^{2,10}\right)$. This classification is relevant for primary care physicians as well as specialists and researchers. The nine main categories are arranged in the acronym PALM-COEIN with each letter denoting a cause: Polyp, Adenomyosis, Leiomyoma (uterine fibroids), Malignancy, Coagulopathy, Ovulatory dysfunction, Endometrial, latrogenic and Not otherwise classified (FIG. 1; TABLE 1). Patients can therefore be said to have, for instance, AUB-P and/or AUB-I. The group of PALM causes relates to the structural causes of AUB, which are generally discrete entities that can be evaluated or measured

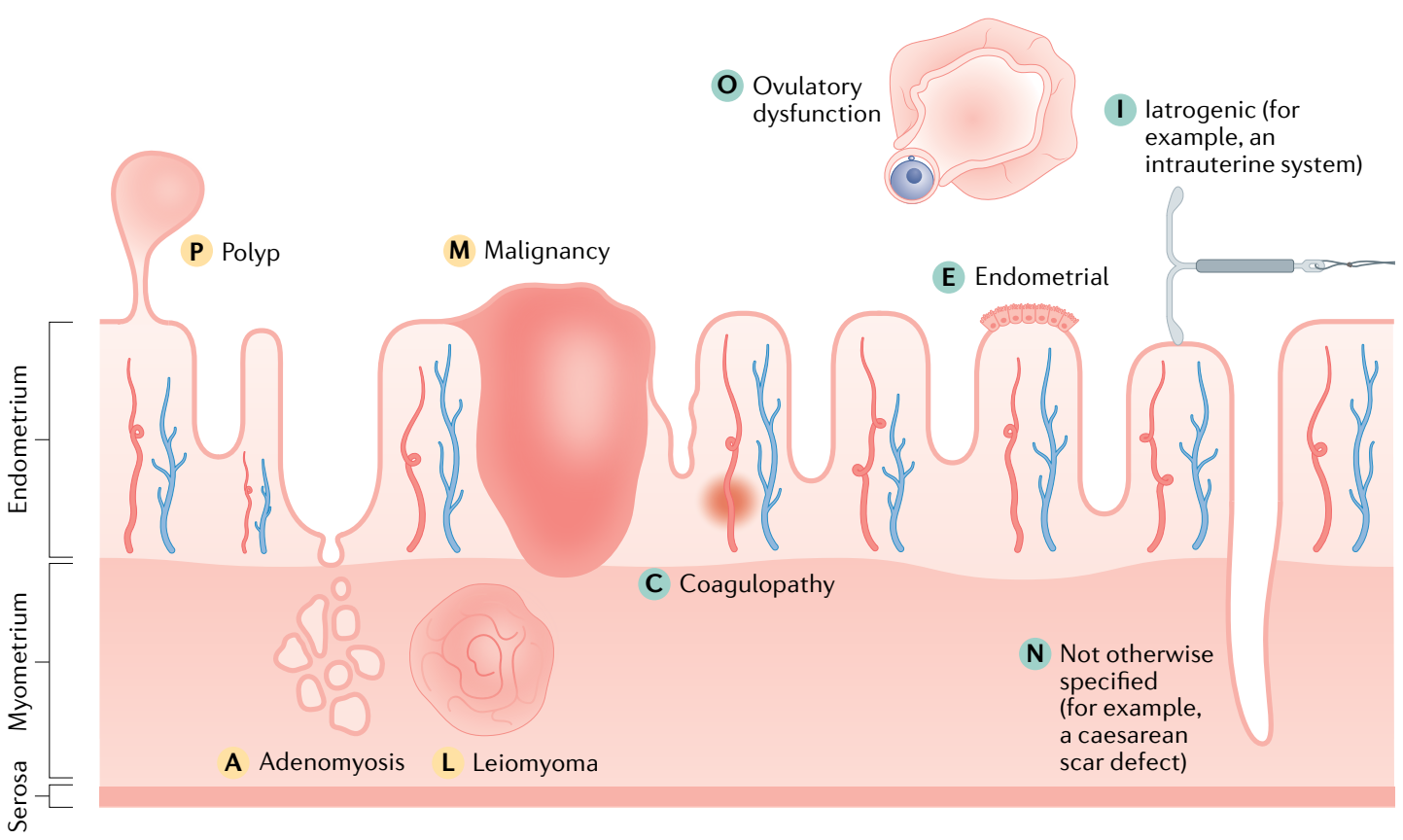

Fig. 1 | FIGO System 2: the PALM-COEIN classification system. The causes of abnormal uterine bleeding are classified using the acronym PALM-COEIN, with each letter denoting a cause. The structural causes (denoted by yellow letters) are discrete entities and include polyp, adenomyosis, leiomyoma (uterine fibroids) and malignancy. The non-structural causes (denoted by green letters) are depicted for the illustration; however, they cannot be measured or imaged. They include coagulopathy, ovulatory dysfunction, endometrial, iatrogenic and not otherwise classified (for example, a caesarean scar defect $)^{2,10}$. Note that the figure is a schematic and is not to scale. 
Table 1 | PALM-COEIN classification of causes of abnormal uterine bleeding

\begin{tabular}{|c|c|c|c|}
\hline Classification & Definition & Global prevalence & Further details \\
\hline Polyp (AUB-P) & $\begin{array}{l}\text { Focal outgrowths of vascular, } \\
\text { glandular, fibromuscular and } \\
\text { connective tissue }\end{array}$ & $\begin{array}{l}10-15 \% \text { of women without AUB } \\
\text { have polyps; } 20-30 \% \text { of women with } \\
\text { AUB have polyps }\end{array}$ & Located in uterine cavity or endocervix \\
\hline $\begin{array}{l}\text { Adenomyosis } \\
\text { (AUB-A) }\end{array}$ & $\begin{array}{l}\text { The presence of ectopic } \\
\text { endometrial glands } \\
\text { and stroma within the } \\
\text { myometrium }^{12}\end{array}$ & $\begin{array}{l}\text { Varies depending on method of } \\
\text { diagnosis and concurrent symptoms } \\
\text { in population being studied; } ; 02 \\
\text { however, an estimate of } 20-35 \% \text { on } \\
\text { average in women with AUB }{ }^{164,203,204}\end{array}$ & $\begin{array}{l}\text { Can be focal or diffuse; primarily affects the } \\
\text { posterior uterine wall }{ }^{143} \text {; an 'elusive' disease, poorly } \\
\text { understood and difficult to diagnose with a vague, } \\
\text { ill-defined pattern of symptoms }{ }^{12}\end{array}$ \\
\hline $\begin{array}{l}\text { Leiomyoma (AUB-L; } \\
\text { uterine fibroids) }\end{array}$ & $\begin{array}{l}\text { Excessive proliferation of } \\
\text { smooth muscle cells and } \\
\text { fibroblasts }\end{array}$ & $\begin{array}{l}\geq 80 \% \text { of all women by age } 50 \text { years } \\
\text { (varies with ethnicity) })^{189}\end{array}$ & $\begin{array}{l}\text { Benign uterine lesions; individuals can have one or } \\
\text { multiple fibroids; sub-classification is dependent on } \\
\text { their uterine location }\end{array}$ \\
\hline $\begin{array}{l}\text { Malignancy and } \\
\text { hyperplasia (AUB-M) }\end{array}$ & $\begin{array}{l}\text { An abnormal proliferation of } \\
\text { cells of the reproductive tract }\end{array}$ & $\begin{array}{l}\text { Atypical endometrial hyperplasia } \\
\text { and genital tract malignancy are } \\
\text { uncommon; prevalence depends } \\
\text { on the tissue of origin of the } \\
\text { malignancy or hyperplasia }\end{array}$ & $\begin{array}{l}\text { An important potential cause to consider in all } \\
\text { women with AUB; the risk of AUB-M increases with } \\
\text { age, especially in perimenopause, in people with } \\
\text { anovulatory cycles, and/or in people with obesity. } \\
\text { WHO or FIGO classification systems should be } \\
\text { followed }\end{array}$ \\
\hline $\begin{array}{l}\text { Coagulopathy } \\
\text { (AUB-C) }\end{array}$ & $\begin{array}{l}\text { A spectrum of systemic } \\
\text { disorders of haemostasis that } \\
\text { can be associated with AUB }\end{array}$ & $\begin{array}{l}\sim 13 \% \text { of patients with } \mathrm{HMB} \text { have } \\
\text { a detectable coagulopathy and } \\
\text { von Willebrand disease is the most } \\
\text { common cause }^{112}\end{array}$ & $\begin{array}{l}\text { Pharmacological intervention that can impair blood } \\
\text { coagulation is included in AUB- } I^{2}\end{array}$ \\
\hline $\begin{array}{l}\text { Ovulatory } \\
\text { dysfunction (AUB-O) }\end{array}$ & $\begin{array}{l}\text { AUB-O is linked with } \\
\text { endocrinopathies, such as } \\
\text { PCOS and hyperprolact- } \\
\text { inaemia (diagnosed with } \\
\text { blood tests); AUB-O can be } \\
\text { linked with mental stress and } \\
\text { extreme (high or low) weight }{ }^{10}\end{array}$ & Dependent on cause & $\begin{array}{l}\text { AUB-O leads to varying bleeding patterns, from } \\
\text { amenorrhoea to HMB; ovulatory disorders linked } \\
\text { with iatrogenic pharmaceutical interventions are } \\
\text { classified under AUB-I }{ }^{2}\end{array}$ \\
\hline Endometrial (AUB-E) & $\begin{array}{l}\text { Primary disorder of the } \\
\text { endometrium; diagnosis of } \\
\text { exclusion }{ }^{10,205}\end{array}$ & Prevalence unknown & $\begin{array}{l}\text { Can involve dysregulation of the mechanisms } \\
\text { regulating the control of endometrial bleeding at } \\
\text { the time of menstruation, such as local endometrial } \\
\text { vasoconstriction, haemostasis and endometrial } \\
\text { repair }\end{array}$ \\
\hline latrogenic (AUB-I) & $\begin{array}{l}\text { Medical interventions and } \\
\text { devices, pharmacological } \\
\text { agents that lead to AUB }\end{array}$ & Dependent on cause & $\begin{array}{l}\text { Medical interventions and devices such as } \\
\text { medicated intrauterine systems (for example, } \\
\text { LNG-IUS) or inert intrauterine systems; } \\
\text { pharmacological agents such as sex steroids, drugs } \\
\text { influencing dopamine metabolism or ovulatory } \\
\text { function, or anticoagulants; it is important to } \\
\text { decipher the origin of unscheduled and/or } \\
\text { breakthrough bleeding }\end{array}$ \\
\hline $\begin{array}{l}\text { Not otherwise } \\
\text { classified (AUB-N) }\end{array}$ & $\begin{array}{l}\text { A spectrum of conditions, } \\
\text { only some of which can } \\
\text { be evaluated or measured } \\
\text { using imaging modalities or } \\
\text { histopathology }\end{array}$ & Dependent on cause & $\begin{array}{l}\text { Includes rarely encountered or ill-defined entities } \\
\text { such as uterine arteriovenous malformations, lower } \\
\text { segment or upper cervical niche (or an isthmocele) } \\
\text { associated with a caesarean section scar defect }{ }^{2,10}\end{array}$ \\
\hline
\end{tabular}

AUB, abnormal uterine bleeding; FIGO, International Federation of Gynecology and Obstetrics; HMB, heavy menstrual bleeding; LNG-IUS, levonorgestrel-releasing intrauterine system; PCOS, polycystic ovary syndrome.

using imaging modalities or histopathology. The COEI causes refer to the non-structural causes of AUB, that is those that cannot be evaluated or measured using imaging or histopathology. The $\mathrm{N}$ (not otherwise classified) group encompasses a spectrum of conditions that might or might not be evaluated or measured using imaging modalities or histopathology, and could ultimately be placed in their own unique category ${ }^{2,10}$.

After assessment, patients can be diagnosed with one or more causes of AUB, which might or might not contribute to their bleeding complaint. For example, a third of women with adenomyosis might be asymptomatic ${ }^{12}$. For the purposes of this Review, we do not focus on malignancies, but on non-malignant conditions that increase the volume and/or frequency of menstruation.

\section{The impact of AUB}

AUB is a common debilitating symptom that is most often not life-threatening but is life-altering ${ }^{13}$. The reported worldwide prevalence of AUB varies greatly from $3 \%$ to $52 \%$, depending on the terminology used, as well as on whether assessments were subjective or objective ${ }^{2,3,14,15}$. Subjective assessments are likely to result in a higher prevalence of AUB than objective assessments as they are based on the woman's personal perceptions of her bleeding. Objective assessments are conducted either via menstrual diaries or by measuring the quantity of menstrual blood on used menstrual products using laboratory tests, for example the alkaline haematin method ${ }^{16}$. Subjective assessments can vary depending on cultural and societal viewpoints; therefore it can be difficult to 
Health-related quality of life score

An individual's or group's

perceived physical or mental

health over time.

Period poverty

Being unable to access

products needed for

menstruation, and/or having

poor knowledge about

menstruation, often due to

financial constraints. compare subjective assessments across countries, or even within particular patient demographic groups within a population. However, in view of the definition of HMB, the subjective assessment of a person's bleeding is what is clinically important. The National Institute for Health and Care Excellence (NICE), Royal College of Obstetricians and Gynaecologists and FIGO estimate that approximately one third of women globally have AUB at some point in their reproductive years ${ }^{1-3}$. A 2019 survey suggested this could be an underestimation due to under-reporting ${ }^{4}$. In 2011, in the UK, it was estimated that in England and Wales approximately 1.5 million women were affected by HMB annually ${ }^{17}$. $\mathrm{HMB}$ is the fourth most common reason for referral to gynaecology services in the UK and approximately $20 \%$ of 1.2 million referrals to specialist gynaecology services concern women with $\mathrm{HMB}$ in the $\mathrm{UK}^{17,18}$.

On average, $30 \%$ of women globally with AUB are anaemic, and this figure increases to approximately $60 \%$ in South Asia, the eastern Mediterranean and Africa, probably due to the combination of dietary deficiencies, AUB and multiple pregnancies ${ }^{19}$. Iron deficiency is one of the commonest micronutrient deficiencies worldwide ${ }^{20}$. Anaemia is a global health issue that is under-recognized and under-reported in both low-income to middle-income countries and high-income countries ${ }^{21}$. In comparison to all other demographic groups, women of reproductive age are most likely to be affected by iron deficiency, which is responsible for approximately $51 \%$ of global cases of anaemia ${ }^{20}$. The prevalence of iron deficiency worldwide is approximately twice as high as iron deficiency anaemia (IDA) ${ }^{22}$. Iron deficiency and IDA lead to impaired oxygen transportation and enzyme reactions, which impacts almost all metabolic pathways in the body. The functional consequences of iron deficiency and IDA include fatigue, reduced exercise capacity, headaches and impaired cognition ${ }^{23,24}$. AUB therefore needs to be recognized as an important cause of iron deficiency and IDA.

\section{Box $1 \mid$ The impact of abnormal uterine bleeding}

- One third of women are affected by abnormal uterine bleeding (AUB) at some point in their reproductive years, leading to life-altering effects ${ }^{2}$.

- AUB affects all members of society; not only the menstruating individual.

- Physical and mental health effects of AUB include heavy menstrual bleeding, flooding accidents, discomfort, tiredness and depression.

- There is a high global prevalence of iron deficiency and iron deficiency anaemia associated with AUB, which is often under-recognized and under-reported.

- AUB can cause strains on relationships and have a negative impact on an individual's social network.

- AUB can lead to social isolation due to mental and physical symptoms.

- AUB can have negative effects on work and job prospects, and can have financial implications.

- There is a high cost to the individual, which could be related to the menstrual products themselves, clothes and/or bedding that are damaged by flooding accidents, loss of earnings due to missed work, missed opportunities at work or school, and also treatment costs in countries where health care is privately funded.

- For society, the economic implications relate to the impact of AUB on a substantial proportion of the workforce, as well as the environmental impact of menstrual products, for example, which might have a broader economic impact.
Women with AUB have a health-related quality of life score below the 25th percentile compared with the general female population of the same age ${ }^{25}$. Menstrual health complaints have an impact on all aspects of an individual's life (BOX 1), including an increased risk of premature death ${ }^{26}$. People are more likely to seek medical advice for HMB for social and physical factors rather than psychological factors ${ }^{1}$. However, $50 \%$ of women with HMB and mental health concerns describe HMB as the cause of their anxiety and depression ${ }^{1,27}$. Structural causes of AUB are more prevalent with advancing reproductive age and might affect reproductive health. Women in high-income countries are, on average, choosing to delay childbirth. For example, in the UK, $50 \%$ of babies are born to women $\geq 30$ years of age ${ }^{28}$. Therefore, structural causes of AUB, such as uterine fibroids, could have a negative impact on reproductive outcomes. These structural causes of AUB could lead to reduced likelihood of natural conception and less successful assisted reproductive techniques, or even contribute to complications of pregnancy ${ }^{29-31}$.

The socioeconomic burden of AUB is high, with total direct and indirect costs in the UK and USA being greater than $£ 1.2$ billion and $\$ 37$ billion, respectively ${ }^{14,25}$. Period poverty affects many people due to work absence and cost of additional menstrual products when experiencing AUB. Treatment costs for AUB are likely to increase due to an increase in the number of people seeking medical treatment for the condition. Additionally, the UK NICE guidance for the investigation of AUB ${ }^{11}$ changed in 2018 to promote more patients being referred for hysteroscopic investigation, which will potentially contribute to rising costs ${ }^{11}$.

During the COVID-19 pandemic, when access to medical care, investigations and treatments were restricted and/or limited, adaptations to care provision for AUB and the deferral of surgical management were essential in ensuring safe and effective care ${ }^{32,33}$. In a post-COVID-19 world, it will be important that political commitment and public engagement do not ignore this often neglected area of women's health ${ }^{34}$.

There have been no novel treatments in routine clinical use for the symptoms of AUB and/or HMB for 20 years, and no non-hormonal treatments for AUB and/or HMB for at least 30 years ${ }^{17}$. There are also no biomarkers in routine use to manage $\mathrm{AUB}^{35}$. Individuals presenting with the symptom of AUB often represent a heterogeneous group, resulting in considerable challenges in offering tailored treatments. High-quality research to fill the gaps in our knowledge of the physiology and pathology of the menstrual cycle is therefore critical to improving our understanding of the condition. This knowledge will enable appropriate phenotyping of patients in keeping with the principles of personalized precision medicine and will facilitate more specific treatments. In turn, these changes could improve women's quality of life and avoid more invasive surgical management.

\section{Menstrual cycle physiology The endometrium}

The endometrium is a multicellular tissue forming the lining of the uterus. The function of the endometrium is to either prepare for embryonic implantation and 
maintain a pregnancy or, in the absence of pregnancy, to shed and repair, that is, menstruate. The uterine endometrium thus undergoes repetitive and physiological cycling of tissue injury and repair every month ${ }^{36}$. The endometrium is characterized by features of rapid repair without residual scarring or loss of function, similar to a fetus in utero ${ }^{37,38}$.

The human endometrium is composed of two layers. The upper two thirds, the functional layer, is shed during menstruation. The basal layer, the lower third of the endometrium (adjacent to the myometrium), does not shed during menses. The functional endometrium is composed of columnar surface epithelium, which covers a multicellular stroma. The stroma contains connective tissue with fibroblast-like stromal cells, a vasculature (including the specialized spiral arteries) and a population of tissue-resident endometrial immune cells, as well as a cyclical traffic of innate immune cells. The population of innate immune cells (both cyclical and tissue-resident immune cells) varies across the menstrual cycle, and these endometrial leukocytes play important roles in the breakdown and repair of endometrial tissue during menses ${ }^{39,40}$ (FIG. 2).

The endometrium is dynamic and highly responsive to the varying circulating levels of the sex steroid hormones ovarian $17 \beta$-oestradiol (oestradiol) and pregn4 -ene-3,20-dione (progesterone). The endometrium is exposed to a series of hormonal changes throughout the menstrual cycle, first to systemic oestradiol, then to oestradiol and progesterone and, in the absence of pregnancy, progesterone withdrawal. As a consequence of this sequential exposure, the endometrium adapts in form and function across the menstrual cycle. Understanding this tightly regulated endocrine environment could help identify new therapeutic strategies for AUB.

\section{The menstrual cycle}

The main phases in the menstrual cycle are the proliferative phase, secretory phase and menstrual phase. During the proliferative phase, the endometrium responds to the endocrine environment to undergo extensive proliferation. This phase is variable in length and oestradiol is the dominant hormone. At ovulation, the oocyte is released from the dominant ovarian follicle. The follicle then transforms into the corpus luteum, which secretes progesterone and leads to a progesterone-dominant secretory phase, typically lasting 14 days. During this phase, in the presence of high levels of oestradiol and progesterone, the cells of the endometrium undergo morphological and functional changes, a process known as decidualization. With the demise of the corpus luteum in the late secretory phase, progesterone and oestradiol levels decline, and the cells of the endometrium are no longer maintained. As a consequence of progesterone withdrawal, there is a coordinated spatial and temporal response in the upper functional layer of the endometrium that culminates in menstruation. Local cellular and molecular events include endometrial apoptosis, inflammatory mediator influx and the induction of matrix metalloproteinase (MMP) expression. The peri-menstrual phase encompasses endometrial transition from the secretory phase, through menstrual breakdown and repair, to regeneration in the proliferative phase. The ovarian equivalent of the peri-menstrual phase is the luteofollicular transition ${ }^{36,41}$ (FIG. 2).

\section{Hormonal influences}

The role of oestradiol and progesterone. The endometrium is a target tissue for steroid hormones and its form and function is entirely governed by the prevailing endocrine environment. Therefore, both endogenous and exogenous hormone exposure affects endometrial bleeding patterns. Oestradiol and progesterone induce their physiological effects in the endometrium primarily via their cognate receptors, the oestrogen receptor (ER) and the progesterone receptor (PR). These receptors, along with receptors for androgens, glucocorticoids and mineralocorticoids, belong to a superfamily of nuclear receptors that act as ligand-activated transcription factors ${ }^{42}$. Current medical treatments for AUB largely focus on hormonal management strategies, using a combination of oestrogen and progestins or progestins alone. Oestrogens and progestins can be delivered through oral preparations, whilst progestins alone can be delivered via medicated intrauterine devices or injections, or as oral forms ${ }^{43}$. The basic mechanism of action of oral combined hormonal regimens is the suppression of ovulation and oestrogen-mediated endometrial proliferation $^{44}$. These treatments might not target the underlying cause of AUB; in fact, one in five women using progestin-only treatments might experience unscheduled bleeding (AUB-I) ${ }^{45}$. Women might also experience hormonal adverse effects due to off-target effects, such as bloating, breast tenderness, acne or mood changes ${ }^{45}$. Improved knowledge of the underlying mechanism of AUB symptoms, for example in AUB-E, might enable better targeting of the local endometrial hormonal environment and reduce off-target action and adverse effects ${ }^{2}$.

The PR is encoded in a single gene located on chromosome 11 (11q22-q23). The PR has two main isoforms, PR-A and PR-B. These isoforms are structurally almost identical, except that PR-A is truncated by 164 amino acids at the amino terminal segment compared with PR-B ${ }^{42}$. PR-A and PR-B act as transcriptional regulators of progesterone responsive genes. $\mathrm{PR}-\mathrm{A}$ is the dominant isoform and, therefore, the primary mediator of progesterone action and an inhibitor of PR-B. The expression of $\mathrm{PR}$ in the uterus is stimulated by oestrogens via the $\alpha$ isoform of ER (ER $\alpha$ ), and therefore progesterone responsiveness is dependent on the presence of an adequate oestrogen response ${ }^{46}$. PR expression exhibits well-described temporal and location expression patterns ${ }^{47}$. The PR is located in nuclei of the endometrial epithelial and stromal cells during the proliferative phase. Expression of PR persists in the nuclei of the stromal compartment of the functional layer of the endometrium during the secretory phase, particularly in the perivascular region ${ }^{47}$.

In the genomic signalling pathway, when progesterone (the PR ligand) binds with PR at its ligand-binding domain, a conformational change occurs and the progesterone-PR complex translocates to the nucleus 
Ovarian cycle

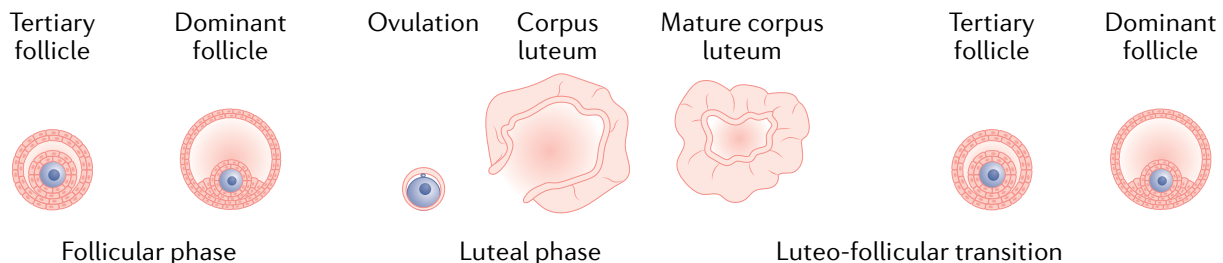

$\begin{array}{ll}\text { Menstrual cycle } & \text { Peri-menstrual phase }\end{array}$
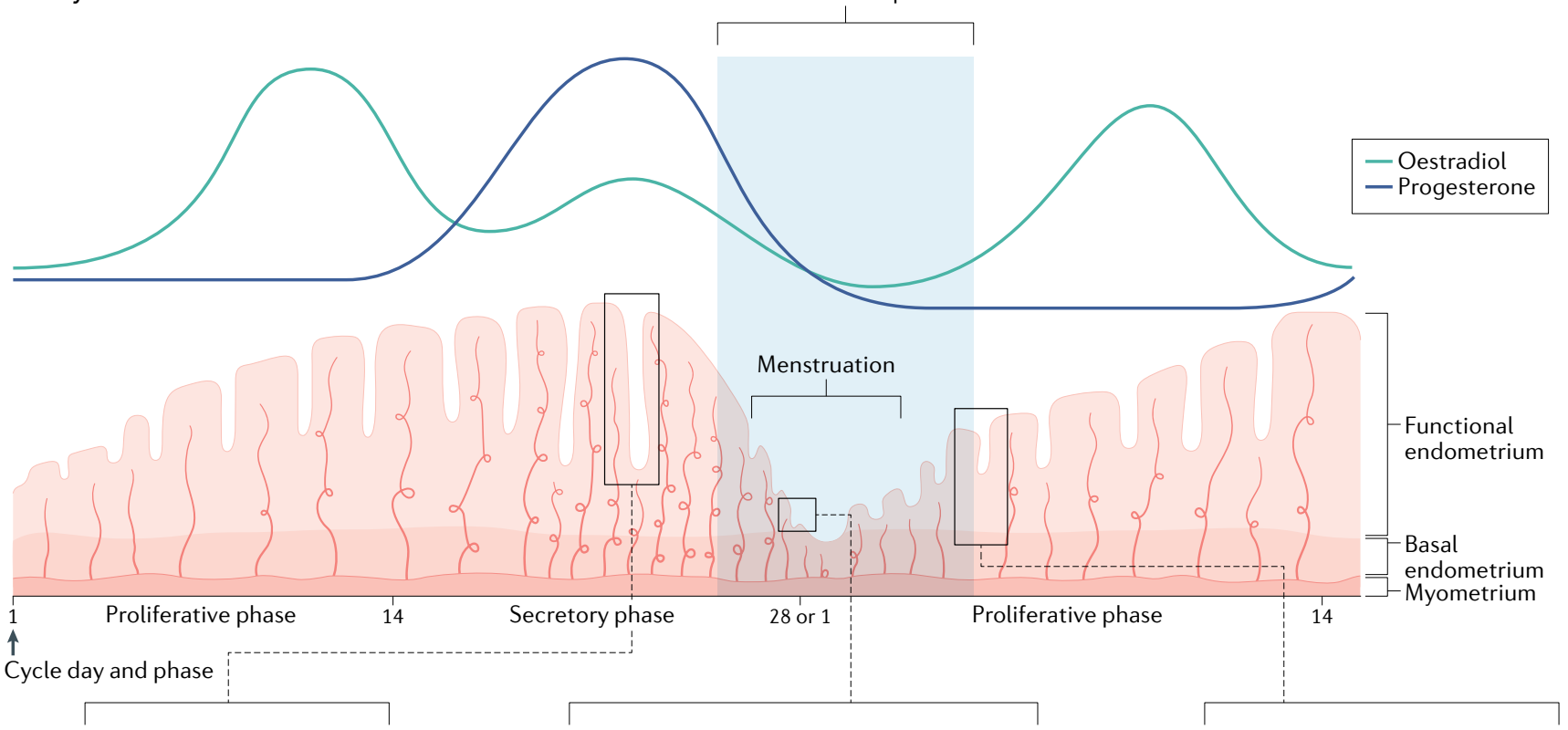

Secretory phase endometrium

Menstrual phase endometrium
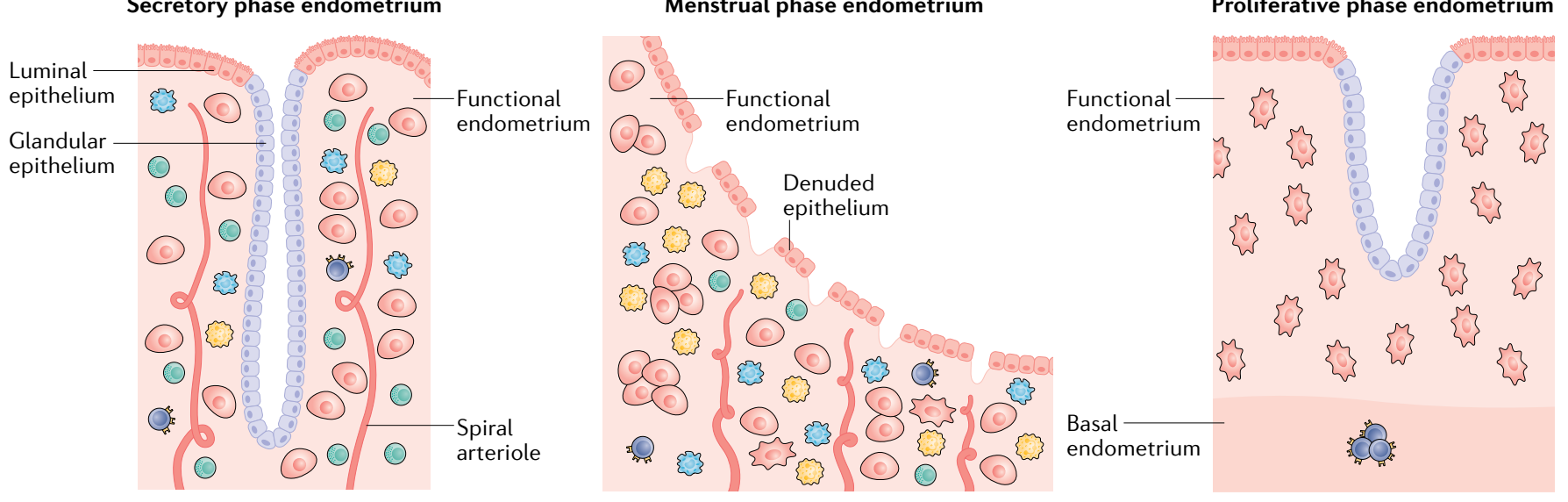

Tlymphocyte

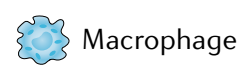

$\left\{\begin{array}{l}3 \\ \text { Neutrophil }\end{array}\right.$ Uterine natural
killer cell

Decidualized stromal cell

$\sum \begin{aligned} & \text { Stromal } \\ & \text { cell }\end{aligned}$

Fig. 2 | Menstrual cycle and ovarian cycle physiology with highlighted aspects of the structure of the endometrium. The endometrium is a dynamic structure that adapts to the endocrine environment in a cyclic manner, on average every 28 days. It undergoes a process of proliferation during an oestradiol-dominant phase. Following ovulation, the corpus luteum secretes progesterone, leading to a progesterone-dominant stage during which the endometrium decidualizes. In the absence of pregnancy, after the demise of the corpus luteum and progesterone withdrawal, the endometrium is shed during menstruation. This process requires the remaining cells to repair and regenerate without injury or scarring so that the menstrual cycle can repeat. As a multicellular tissue, the endometrium is highly responsive to the endocrine environment. The lower third of the endometrium, adjacent to the myometrium, is known as the basal layer and the upper two thirds, including the luminal surface, as the functional layer. Under the influence of changing levels of oestradiol and progesterone, the cellular structure of the endometrium adapts. The main cellular components within the endometrium are the epithelial cells, stromal cells, vascular cells and a variety of innate immune cells. The numbers of immune cells vary according to the cycle stage (see Figure key). The functional layer is shed during the menstrual phase, leaving behind a denuded basal endometrium. The peri-menstrual phase (also known as the luteofollicular transition) is the time after which progesterone and oestradiol levels fall, menstruation occurs and the endometrium transitions from a secretory to a proliferative state $^{36,41,97}$. Note that the figure is a schematic and is not to scale. 
Progesterone receptor modulator-associated endometrial change Histological endometrial changes, which are benign and reversible, found after selective progesterone receptor modulator use. of the cell. The progesterone-PR complex interacts with transcriptional components and binds with progesterone response elements within target genes. Co-regulatory proteins are required to implement transcription-modifying effects, and these will either enhance (co-activators) or decrease (co-repressors) the level of transcriptional activity $^{48,49}$. The PR has been the target for the development of specific therapies to modulate and/or reduce endometrial bleeding, specifically the class of compounds known as selective PR modulators (SPRMs) ${ }^{48,50}$.

SPRMs are exceptionally effective in reducing menstrual blood loss and creating amenorrhoea, which affects both endometrial morphology and function ${ }^{48}$. Treatment with any of the SPRMs studied to date leads to development of a distinct histological entity described as proge sterone receptor modulator-associated endometrial changes $(\text { PAEC })^{51}$. PAEC are currently understood to be benign and histologically reversible ${ }^{51}$. There is still a dearth of evidence concerning the impact that the interactions between SPRMs and PR might have upon endometrial molecular and cellular signatures (such as gene and protein expression) when people are using SPRMs. Data published this year, however, indicate that the paradoxical reduction in endometrial cell proliferation and the modulation in endometrial morphology and function seen with SPRM treatment appear reversible following cessation of drug exposure ${ }^{52}$.
Two separate ER isoforms have been identified: ERa, encoded by the ESR 1 gene, and ER $\beta$, encoded by the ESR2 gene ${ }^{53-56}$. Expression of variant isoforms of both ER subtypes in the human endometrium, formed by translation of mRNAs generated by alternative splicing of the ESR1 and ESR2 genes, have also been described. ESR1 $(\mathrm{ER} \alpha)$ is located on chromosome 6, whilst ESR2 (ER $\beta)$ is found on chromosome 10 . Oestrogen is a ligand for the ER and downstream effects of oestrogen signalling, such as cellular proliferation and differentiation, occur in a similar manner to progesterone binding with $\mathrm{PR}^{57}$. $\mathrm{ER} \alpha$ and $\mathrm{ER} \beta$ are both expressed in the glandular epithelium and the stroma in the proliferative phase, which is when the peak concentrations of ER are observed. During the secretory phase, ERa levels decline in both the endometrial glandular epithelium and stroma. $\operatorname{ER} \beta$ levels also decline in the glandular epithelium in the secretory phase; however, ER $\beta$ expression is maintained in the endometrial stroma ${ }^{58}$.

Sex steroid hormone biosynthesis. The availability of biologically active sex steroids within the endometrium is dependent on the action of local endometrial sex steroid-metabolizing enzymes ${ }^{59}$ (FIG. 3). Locally produced sex steroids can exert their action in the cells in which they are synthesized, without release into the extracellular space, a concept known as intracrinology ${ }^{60}$.

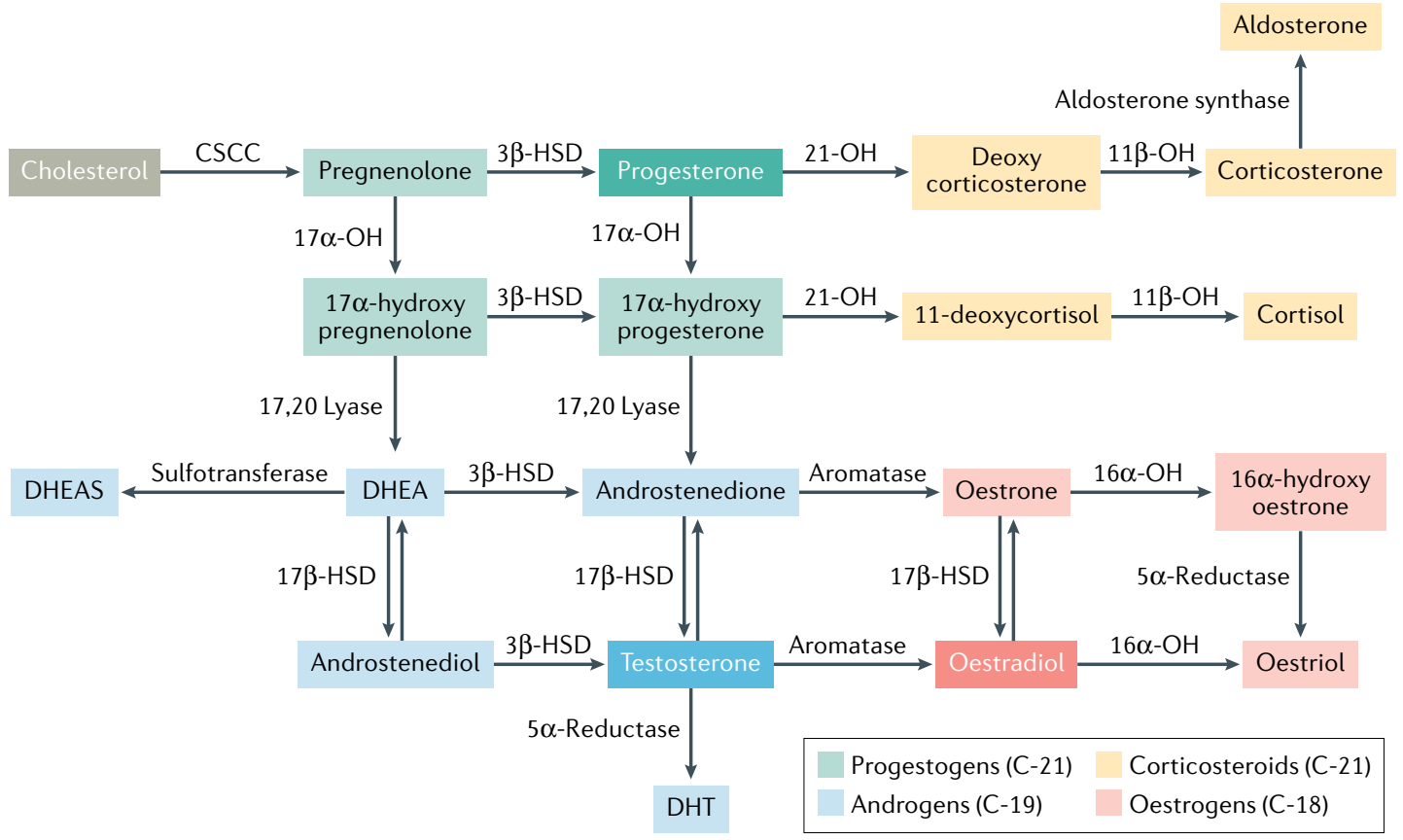

Fig. 3 | Major biosynthetic pathways in steroidogenesis. The precursor of all steroid hormones is cholesterol. Steroidogenesis (synthesis of steroid hormones) occurs predominantly in the adrenal glands and gonads (ovaries and testes); however, it also occurs in the placenta. The key enzymes are located in the mitochondria and the endoplasmic reticulum of the cell. The first step in steroidogenesis involves the conversion of cholesterol to pregnenolone (a non-hormonal intermediate) within the cell mitochondria by the cholesterol side chain cleavage (CSCC) enzyme. The major classes of steroid hormones include progestogens, androgens, oestrogens and corticosteroids (glucocorticoids and mineralocorticoids). All steroid hormones have a cyclopentanoperhydrophenanthrene ring, and are further classified based on the number of carbon atoms. Pregnanes have 21 carbon atoms and are called C21 steroids (progestogens and corticosteroids). Oestranes have 18 carbon atoms (C18 steroids) and include oestrogens. Androstanes have 19 carbon atoms (C19 steroids) and include androgens. OH, hydrolase; HSD, hydroxysteroid dehydrogenase; DHT, dihydrotestosterone; DHEA, dehydroepiandrosterone; DHEAS, dehydroepiandrosterone sulfate. 
The local endocrine milieu plays a crucial role in the regulation of endometrial function. For example, pharmacological manipulation of the PR with SPRM treatment could result in molecular and cellular modifications in local sex steroid availability in the endometrium, as well as changes in the availability of local sex steroid metabolizing enzymes. These modifications could result in the creation of a local endometrial oestrogenic microenvironment ${ }^{52}$. Similarly, local delivery of a progestin could consequently also modify the local endometrial steroid microenvironment. For example, the progestin levonorgestrel, which can be delivered via an intrauterine system, modulates endometrial PR expression $^{61}$.

The intracrinology of the human endometrium more generally was comprehensively reviewed in 2018 $\left(\right.$ REF $\left.^{62}\right)$. Endometrial steroid hormone metabolism studies, which extend over nearly 50 years, initially demonstrated steroid sulfatase activity, and these were followed by studies concerning oxidative and reductive $17 \beta$-hydroxysteroid dehydrogenase (17 $\beta$-HSD) activities $^{59}$. These steroid-metabolizing enzymes are involved in endometrial steroid hormone (ligand) availability and thus are involved with modulation of the local endometrial hormone environment. De novo steroid biosynthesis requires cholesterol, which is shuttled to the inner mitochondrial membrane by steroidogenic acute regulatory protein, where it undergoes side chain cleavage by CYP11A1 (a member of the cytochrome P450 superfamily of enzymes that is involved in lipid synthesis) to yield pregnenolone. Pregnenolone undergoes two enzymatic conversions mediated via CYP17A1, first to $17 \alpha$-hydroxypregnenolone (17a-hydroxylase activity) and then, following 17,20 lyase action, to dehydroepiandrosterone (DHEA). Expression of steroidogenic acute regulatory protein, CYP11A1 and CYP17A1 has been reported in the endometrium ${ }^{59,63}$. However, no study has identified definitive de novo steroidogenesis from normal endometrial tissue. DHEA is normally synthesized in the ovary and adrenal glands and released into the circulation $^{59}$.

The endometrium exhibits both oxidative and reductive $17 \beta$-HSD activities and the expression of $17 \beta$-HSD1, $2,4,6,7,8,10,12$ and 14, and 17 $\beta$-HSD5 (also known as aldo-keto reductase family 1 member C3, AKR1C3) are detected at the mRNA or protein levels. The endometrium also has the capacity to metabolize sulfated compounds and DHEA to form androgens and oestrogens ${ }^{62}$ (FIG. 3). DHEA is converted to androstenedione by $3 \beta-\mathrm{HSD}$, which is expressed in endometrial stromal cells. The steroid-metabolizing enzyme, $17 \beta$-HSD2, is responsible for conversion of oestradiol and testosterone to oestrone and androstenedione (which has a reduced biological activity), respectively, and conversion of 20-hydroxyprogesterone to biologically active progesterone. The endometrial steroid-metabolizing enzyme $17 \beta$-HSD 5 has the opposite effects. A balance between the activity of these major steroid-regulating enzymes and others (such as aromatase) play key roles in the local endometrial milieu and endocrine regulation of menstruation. Studies have indicated that serum concentrations of steroid hormones differ from local endometrial concentrations of these hormones and are consistent with local enzyme regulation ${ }^{59,64}$.

The role of androgens and glucocorticoids. As well as oestradiol and progesterone, androgens ${ }^{59}$ and glucocorticoids ${ }^{65}$ play an important role in the regulation of endometrial function. Therefore, hormone equivalents or drugs that modulate the androgen receptor or glucocorticoid receptor could also act as potential therapeutic targets in AUB management. Androgen receptor expression varies throughout the menstrual cycle in the functional layer of the endometrium, both in the stroma and epithelial cells. The androgen receptor is predominantly expressed in the endometrial stroma during the proliferative phase, with reduced expression during the secretory phase. Androgen receptor expression has been observed in the endometrial glands in the late secretory or decidualized phase ${ }^{66}$. Androgens have been found to impact the proliferation, migration and survival of stromal cells within the endometrium in humans ${ }^{67}$. Using a mouse model of simulated menses, an injection of the androgen dihydrotestosterone at the time of progesterone withdrawal led to delayed repair of the luminal epithelium, indicating that androgens are involved in impairment of endometrial repair and could be involved in altered menstruation ${ }^{6}$. Androgens have an antiproliferative effect on both endometrial epithelial and stromal cells $s^{63}$. Androgens have been shown to upregulate decidualization markers on human endometrial stromal cells in vitro and might have a role to play in wound healing ${ }^{68,69}$. However, the role of androgens in wound healing is not fully understood in humans. In a mouse model of simulated menses, androgens have been shown to alter the expression of MMPs and caspase 3, altering the balance of apoptosis and repair within the endometrium, and therefore endometrial integrity ${ }^{68}$. The menstruating endometrium is an example of a wounded mucosal surface that rapidly repairs ${ }^{36,70}$.

Altered androgen signalling has also been identified in endometrial cancer and endometriosis. Insights from 2018 suggest that androgens might have dual roles in the endometrium and could modulate endometrial function by acting directly on the androgen receptor and acting indirectly as precursors to local oestrogens ${ }^{63}$. The development of selective androgen receptor modulators ${ }^{71}$ might identify new therapeutic targets for treating AUB.

Glucocorticoids have an anti-inflammatory effect that is mediated by cortisol binding to the glucocorticoid receptor in the stromal, epithelial and uterine natural killer cells ${ }^{72}$. Cortisol also inhibits angiogenesis by interacting directly with glucocorticoid receptors on vascular endothelium $^{73}$. The enzyme $11 \beta$-HSD1 converts the less potent cortisone into cortisol, a biologically active molecule, and the reverse reaction is catalysed by $11 \beta-\mathrm{HSD} 2$ (REF. ${ }^{74}$ ). 11 $\beta$-HSD1 activates cortisol, and is upregulated at the time of menstruation, which coincides with the maximal endometrial levels of the glucocorticoid receptor, which enables cortisol to have maximal effect $^{65} .11 \beta$-HSD2 inactivates cortisol and women with objectively assessed HMB have been reported to have a 2.5 -fold increase in levels of $11 \beta$-HSD2 compared with women without $\mathrm{HMB}^{75}$. This increase in levels of 
$11 \beta$-HSD2 could lead to increased angiogenesis and impaired vasoconstriction due to reduced endometrial cortisol availability, which might in turn result in $\mathrm{HMB}^{75}$. Oral dexamethasone, a synthetic glucocorticoid with a high affinity for the glucocorticoid receptor and low affinity for inactivation by $11 \beta$-HSD2, has been evaluated in the DexFEM (Dexamethasone For Excessive Menstruation) clinical trial as a potential therapeutic target for HMB (ClinicalTrials.gov NCT01769820; EudraCT 2012-003405-98 $)^{76}$. The underpinning principle of this trial is that correction of a hypothesized local endometrial cortisol deficiency using low-dose dexamethasone might improve HMB symptoms. The DexFEM study, published in 2021 (REF. ${ }^{77}$ ), found the first evidence of a therapeutic benefit of dexamethasone in the management of HMB. The findings of this adaptive, randomized controlled trial are generalizable to the range of women seeking treatment for HMB. The study showed that oral administration of $0.9 \mathrm{mg}$ of dexamethasone twice daily for 5 days in the luteal phase reduces objectively measured menstrual blood loss.

\section{Decidualization}

Decidualization is a progesterone-dependent process that ensures the endometrium adapts from a proliferative phenotype to one that will nurture and support a pregnancy. It is a spontaneous occurrence in the human endometrium as it does not require the presence of an embryo $^{78}$. Decidualization occurs due to a rise in progesterone secreted by the corpus luteum following ovulation and the production of cAMP throughout the endometrial stroma ${ }^{36}$. In the absence of embryo implantation, progesterone levels fall and spontaneous decidualization leads to menstrual shedding and cyclic regeneration of the endometrium ${ }^{78}$.

During decidualization, progesterone targets the endometrial stromal cells, resulting in their transformation from an elongated to a rounded morphology. In addition, progesterone induces the expression of progesterone-dependent proteins, such as prolactin, glycogen, tissue factor, insulin-like growth factor binding protein 1 and forkhead box protein $\mathrm{O} 1$. This process leads to a unique genetic signature within the individual cell types of the endometrium (stromal fibroblasts, endothelial cells, macrophages, lymphocytes and epithelial cells), and, thus, the unique genetic signature could be a plausible biomarker of endometrial receptivity and progesterone response $\mathrm{e}^{79,80}$.

'Progesterone resistance' is a term used to describe an abnormal endometrial response to the post-ovulatory increase in progesterone levels, and often manifests as a deficient decidualization response ${ }^{81}$. Progesterone resistance has been described in patients with adenomyosis and it is reported that ER $\beta$ expression and PR expression are perturbed in patients with HMB and adenomyosis, which is in contrast to expression levels in those women with $\mathrm{HMB}$ and no evidence of adenomyosis ${ }^{82}$. It is interesting that lower levels of HOXA10 expression (a progesterone-regulated gene) have been reported in the secretory endometrium of women with HMB and uterine fibroids than in the secretory endometrium of women without uterine fibroids and with normal menstrual bleeding ${ }^{52,83,84}$, suggesting that women with uterine fibroids might have developed progesterone resistance. A blunted or inadequate response to progesterone might therefore interfere with decidualization and expression of progesterone-regulated genes. Progesterone is responsible for endometrial differentiation and decidualization in an oestradiol primed endometrium $^{42}$, and dysregulation of progesterone signalling might therefore contribute to AUB.

Appropriate endometrial cell proliferation and decidualization results in primed decidualized stromal cells that are sensitive to their hormonal environment. Decidualization has been suggested to be a prerequisite for menstruation ${ }^{36}$ as spontaneous decidualization does not occur in non-menstruating animals. However, the impact of the decidualization process on menstrual blood loss parameters remains to be determined.

\section{Menstruation}

Initiation of menstruation. Menstruation occurs after the demise of the corpus luteum and the withdrawal of progesterone and oestradiol, triggering local endometrial apoptosis, inflammation, hypoxia and tissue breakdown. There are two components to the processes underlying the menstrual phase, the first being progesterone-dependent and the second being progesterone-independent ${ }^{85}$. Once progesterone, an anti-inflammatory hormone, is withdrawn, the endometrium is exposed to a local environment rich in cytokines and prostaglandins. The generation of inflammatory mediators is coordinated by the actions of the NF- $\kappa \mathrm{B}$ transcription factor, which regulates genes involved in the inflammatory process. During the progesterone-dominant secretory phase of the menstrual cycle, progesterone inhibits NF- $\mathrm{BB}$, but with progesterone withdrawal in the late secretory phase, this inhibitory effect is no longer present. NF- $\kappa \mathrm{B}$ subsequently degrades its inhibitor, I $\mathrm{B} a$, which leads to a local endometrial increase in cytokines, chemokines and MMP production ${ }^{86}$.

Inhibition of MMP activity in response to circulating oestradiol and progesterone maintains the secretory endometrium. This inhibition is reversed after withdrawal of progesterone, and the reversal of the inhibition of MMP activity upregulates pro-MMPs, at least in part via NF- $\kappa B$ activity ${ }^{87}$. Upregulation of MMPs and associated menstruation is related to progesterone withdrawal rather than oestrogen decline in the late secretory phase of the menstrual cycle ${ }^{88}$. Apoptosis has been demonstrated to occur in the glandular epithelium and then the stromal compartment prior to endometrial shedding in human endometrial samples from the late secretory phase, after progesterone withdrawal ${ }^{41}$. This observation was recapitulated in a mouse model of menstruation, providing support for this preclinical model in menstrual research ${ }^{41}$.

As a result of increased levels of cytokines and chemokines in the endometrium, there is an influx of innate immune cells within the endometrium, activation of MMPs and degradation of the extracellular matrix $^{89}$. Using carefully timed insertion and removal of progesterone implants in non-human primate and 
mouse models of menstruation, it has been demonstrated that there is a threshold within the menstrual phase when the endometrium is no longer responsive to the anti-inflammatory effects of progesterone and menstrual bleeding is inevitable ${ }^{90-93}$. Disruptions in these pathways can lead to increased inflammation, resulting in AUB- $\mathrm{E}^{2}$. Progesterone withdrawal, and the subsequent inflammatory cascade, culminates in menstruation ${ }^{94}$. Destruction and shedding of the functional layer (bleeding as menstruation) ensue in a piecemeal fashion, leaving a denuded endometrial surface that undergoes concurrent repair $^{70}$.

Control of endometrial bleeding. In order for tissue regeneration to occur, three factors must coordinate to ensure a timely cessation of menstrual bleeding. First, vasoconstriction of spiral arterioles must occur. The efficient vasoconstriction of endometrial arterioles is necessary to limit menstrual blood flow. According to the Poiseuille equation, a small increase in the vessel radius will dramatically increase flow through the vessel ${ }^{95}$. For example, a twofold increase in vessel radius leads to a 16-fold decrease in resistance to flow. Second, an effective haemostatic response is required, including repair of damaged vasculature ${ }^{36}$. Third, appropriately timed re-epithelialization of the denuded basal endometrium is necessary ${ }^{96,97}$.

Decreased vasoconstriction during menstruation could be due to abnormal production of vasoactive factors following progesterone withdrawal. Examples of these factors include a decreased $\mathrm{PGF}_{2 \alpha}$ to $\mathrm{PGE}_{2}$ ratio, decreased prostaglandin $\mathrm{F}$ receptor expression, increased $\mathrm{PGE}_{2}$ production, decreased levels of endothelin 1 (a potent vasoconstrictor) and increased levels of neural endopeptidase, the enzyme that metabolizes endothelin 1. Spiral arterioles in women with HMB are larger in diameter than those in women without HMB due to altered maturation throughout the menstrual cycle. This altered maturation could be due to increased expression of VEGFA and VEGF receptors 1 and 2 $\left(\right.$ REF. $\left.^{98}\right)$. Women with HMB have reduced vascular smooth muscle (VSM) cell proliferation in spiral arterioles compared with women without $\mathrm{HMB}^{99}$. This reduced proliferation might effect vascular tone and VSM contractility, thereby reducing the hypoxic response and leading to excessive bleeding (AUB-E).

Evidence indicates that the alterations in VSM maturation in women with HMB are linked to reduced myosin heavy chain expression in the spiral arterioles in the early secretory stage. This reduced expression might, in turn, be correlated with expression of specific VSM mitogens (for example, endothelin ${ }^{100}$ ) in the endometrium in women with HMB. Further supporting the importance of endometrial vascular maturation in reducing menstrual blood loss is the identification of roles for the growth factor transforming growth factor $\beta 1$ (TGF $\beta 1$ ). TGF $\beta 1$ is involved with phenotype switching of VSM cells to a contractile phenotype and is also required for repair of the denuded menstrual endometrium ${ }^{101}$. There is evidence of decreased TGF $\beta 1$ bioavailability and signalling in the endometrium of women with $\mathrm{HMB}^{101,102}$, suggesting that TGF $\beta 1$ signalling and bioavailability could be potential therapeutic targets for the treatment of $\mathrm{HMB}$ in the future.

The role of hypoxia. The presence of hypoxia within the endometrium was proposed 80 years ago after the observation of transplanted endometrium on the anterior chamber of the eye of rhesus macaques ${ }^{103}$. Transplanted endometrium was observed for a combined total of 432 menstrual cycles, especially during menstruation, and progesterone withdrawal and intense vasoconstriction in the spiral arterioles was considered to induce hypoxia. The presence of hypoxia during endometrial breakdown and repair has also been demonstrated in a mouse model of simulated menstruation ${ }^{104-106}$. Mice were also placed in hyperoxic conditions following progesterone withdrawal, which prevented the development of hypoxia during menstruation. This lack of hypoxia resulted in delayed endometrial repair ${ }^{105}$. This finding is consistent with hypoxia being necessary for efficient endometrial repair at menses.

Hypoxia-inducible factor (HIF) is composed of an a and a $\beta$ subunit and is the master regulator of the cellular response to hypoxia ${ }^{107}$. In normoxia, the a subunit is rapidly degraded by the proteasome and HIF is inactive. Degradation of HIF1 $\alpha$ is prevented under hypoxic conditions. HIF1 $\alpha$ can then bind to its $\beta$ subunit and increase transcription of target genes containing a hypoxia response element. This increase in transcription initiates the expression of host of factors involved in metabolism, angiogenesis and tissue repair, including VEGF ${ }^{108}$.

HIF1a is only present in the human endometrium around the time of menstruation ${ }^{105,109}$. Women with HMB had decreased expression of endometrial HIF1a protein and downstream target genes at menstruation compared with those with normal menstrual blood loss. In addition, women with HMB bled for 2 more days during menstruation than women without $\mathrm{HMB}^{105}$. A mouse model of menstruation with a genetic reduction in HIF1 a revealed statistically significantly delayed endometrial repair following menstruation. This finding was consistent with HIFla having a key role in the hypoxia-mediated menstrual repair process. The delayed repair in a non-hypoxic mouse model of menstruation could be rescued with a pharmacological compound that stabilizes HIF1 $\alpha$, identifying a potential non-hormonal therapeutic target in women with AUB- $\mathrm{E}^{94}$.

Endometrial haemostasis and the coagulation system. Endometrial fibrinolysis plays an important role in normal menstruation and limitation of menstrual blood loss. At menses, disruption of blood vessels after 'endometrial injury' results in adherence of platelets to collagen on an injured basement membrane ${ }^{36}$. Platelet aggregation prompts a coagulation cascade. The coagulation cascade is activated by two pathways: extrinsic and intrinsic. Each cascade results in the conversion of factor $\mathrm{X}$ to $\mathrm{Xa}$, which catalyses the conversion of pro-thrombin to thrombin, ultimately leading to the formation of a fibrin $\operatorname{clot}^{110}$. The fibrinolytic system mediates degradation of the fibrin clot. Fibrinolysis involves conversion of plasminogen to active plasmin, promoting the degradation of fibrin deposits.
The dissolution of fibrin by enzymatic action. 
Plasminogen is converted into plasmin by tissue plasminogen activator during fibrinolysis. Plasmin promotes the degradation of fibrin deposits, which leads to the formation of D-dimers. Menstrual blood contains a high concentration of D-dimers and this component of menstrual blood could be a tool to distinguish menstrual from peripheral blood for forensic purposes ${ }^{111}$. Disorders involving altered systemic haemostasis severely affect menstrual blood loss (AUB-C) ${ }^{112}$. Tissue plasminogen activator and urokinase plasminogen activator orchestrate production of plasmin. Plasminogen activator inhibitor 1 (PAI1) inhibits fibrinolytic activity and has important regulatory functions in haemostasis, turnover of the extracellular matrix and cell adhesion ${ }^{113}$.

Human endometrium expresses tissue plasminogen activator, urokinase plasminogen activator, PAI1 and the urokinase plasminogen activator receptor ${ }^{114,115}$. Levels of the PAI1 protein and mRNA are reportedly increased by progesterone and TGF $\beta 1\left(\mathrm{REF}^{113}\right)$. As discussed in a previous section, decreased TGF $\beta 1$ activity might hinder repair of the denuded menstrual endometrium, leading to $\mathrm{HMB}^{102,113}$. Women with $\mathrm{HMB}$ are reported to exhibit raised levels of tissue plasminogen activator activity on day 2 of menses, possibly due to over activity of the endometrial fibrinolytic system ${ }^{115}$. Such observations support a biological basis for the utility of anti-fibrinolytic drugs (such as tranexamic acid) to reduce menstrual bleeding. Such anti-fibrinolytic medications have been used as a therapy for HMB for the past 30 years ${ }^{116}$.

\section{Tissue repair and regeneration}

Tissue formation and remodelling of the endometrium commences alongside menstruation, with the epithelium forming a new luminal surface. These processes occur prior to stromal cell proliferation of the next menstrual cycle. The processes involved in endometrial repair and regeneration have not yet been fully delineated. Three theories exist as to how the endometrium repairs and regenerates.

The first theory is that epithelial cells, from the exposed stumps of endometrial glands (mainly in the basal layer) or from any intact epithelium bordering the denuded areas of stromal tissue, proliferate to create a new functional luminal layer ${ }^{97,117}$. Another theory is that endometrial stromal cells might be reprogrammed at menstruation to lose their mesenchymal cell characteristics and achieve epithelial cell characteristics through a process called mesenchymal to epithelial transformation (MET). Evidence for MET was found in a mouse model of simulated menses and suggests that both the residual basal layer and the unshed functional layer of the endometrium lead to the re-epithelialization of the remaining denuded epithelium. However, lineage tracing in adult mice showed no definitive evidence for MET in the uterine epithelium ${ }^{118}$. The third theory of how endometrial repair and regeneration occurs after menstruation is that endometrial stem cells and progenitor cells in the basal layer differentiate into stromal, glandular or luminal epithelial cells during the regeneration process.

Evidence for the existence of endometrial stem cells comes from both human and mouse studies ${ }^{119-122}$. Bone marrow-derived stem cells have also been found to supplement the endometrial stem cell population and assist in the regeneration of the endometrium ${ }^{123,124}$. However, their contribution to endometrial regeneration remains controversial, with chimaera mouse models revealing no contribution to endometrial cell lineages. These findings suggest that previously identified bone marrow cells in the uterus were misidentified, possibly due to suboptimal staining and imaging of the CD $45^{+}$ macrophages ${ }^{125-127}$. Further research to delineate this fundamental endometrial repair process in health and disease is essential to facilitate future pharmacological interventions to limit menstrual blood loss.

\section{The myometrium in menstrual bleeding}

The myometrium is composed of smooth muscle that contracts in different directions dependent on the phase of the menstrual cycle. It contracts in an antegrade (fundus to cervix) manner at the time of menstruation to extrude menstrual debris, and then retrograde (cervix to fundus) myometrial contractions might be required to facilitate sperm transport towards the uterine cavity. Myometrial smooth muscle cell contractility decreases with age, suggesting that ageing causes a functional change to the cells ${ }^{128}$. These myometrial contractions, also known as endometrial waves, originate mainly from the sub-endometrial layer of the myometrium. In the early follicular phase, endometrial waves occur once or twice a minute, last $10-15 \mathrm{~s}$ and have a low amplitude. During ovulation, this frequency increases to three to four times per minute. In the luteal phase, the frequency and amplitude of endometrial waves decreases to facilitate embryo implantation. In the absence of implantation, their frequency remains low, but their amplitude increases dramatically ${ }^{129}$.

Pathological structural features commonly present in the myometrium are uterine fibroids and adenomyosis. The aetiopathogenesis of uterine fibroids is complex and poorly understood. Genetic factors, epigenetic factors, endocrine disrupting chemicals, dietary deficiencies (such as vitamin D deficiency), age, race, ethnicity, family history, ovarian steroids, cytokines and growth factors have all been implicated in the development of uterine fibroids, amongst other factors ${ }^{130,131}$. The pathogenic mechanisms involved in the formation of adenomyosis are still to be elucidated. The most common theory underpinning the development of adenomyosis is that the basal endometrium invaginates into the myometrium via an altered or interrupted junctional zone ${ }^{132,133}$. Alternative hypotheses include the mechanism of "Tissue Injury And Repair" (TIAR) ${ }^{134}$. It is known that the endometrium is 'injured' during the process of menstruation but it is unknown exactly how the repair processes occur. During the process of TIAR at the endometrial to myometrial interface adenomyosis might develop as a result of a problem in these TIAR mechanisms and endometrial cells might become incorrectly located in the myometrium ${ }^{134,135}$. A third hypothesis in the development of adenomyosis is via the involvement of endometrial stem cells ${ }^{132}$. Adenomyotic foci within the myometrium can be considered as wounds undergoing repeated TIAR with associated epithelial to mesenchymal transition ${ }^{134}$, fibroblast to myofibroblast transdifferentiation and smooth 
Secondary endometrial

disorder

A disorder in the phenotype of the endometrium as a result of the presence of a structural cause of abnormal uterine bleeding in the myometrium; for example, fibroids or adenomyosis muscle metaplasia, causing the adenomyotic foci to become progressively more fibrotic ${ }^{136}$. Research gaps exist in our knowledge about the pathogenesis of uterine fibroids and adenomyosis and there are currently no evidence-based strategies to prevent their development.

It is currently unclear how structural myometrial conditions such as uterine fibroids and adenomyosis result in the symptoms of not only HMB but also pelvic pain. Pelvic pain linked to adenomyosis has been suggested to be caused by an upregulation of oxytocin receptors, which might cause increased myometrial contraction activity ${ }^{137}$. It is currently unknown if myometrial conditions such as uterine fibroids or adenomyosis interact with the endometrium to alter its phenotype, thereby leading to a secondary endometrial disorder and the abnormal phenotype of HMB (AUB-A or AUB-L) ${ }^{138}$ (FIG. 4).

\section{Improving the management of AUB Nomenclature}

Targeting the unmet clinical need related to AUB requires a collective effort from the scientific community. A lack of consistent terminology within reproductive health research has had a negative impact on scientific advances and clinical management ${ }^{139}$. The FIGO MDC updated its terminologies and definitions of normal and AUB in $2018\left(\mathrm{REFS}^{2,10}\right)$. These efforts to use consistent nomenclature and definitions have led to widespread acceptance of the term 'abnormal uterine bleeding' to describe bleeding that is abnormal in duration, frequency, regularity and volume. Inconsistent terms such as menorrhagia (an out of date term for HMB),

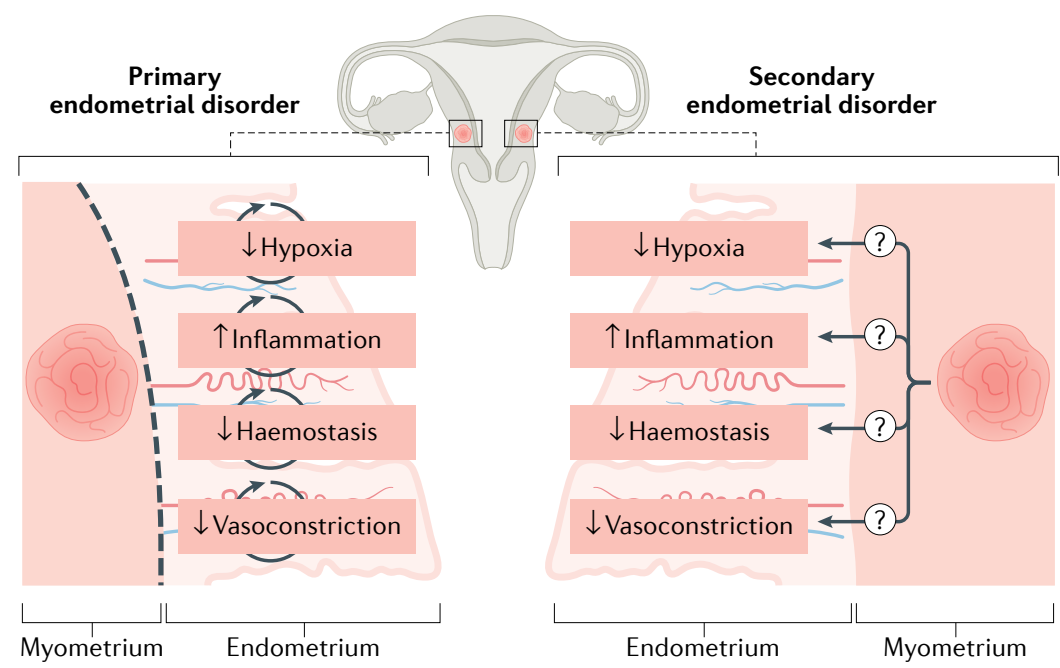

Fig. 4 | The impact of the presence of uterine fibroids (leiomyoma) or adenomyosis on endometrial bleeding. In the presence of myometrial conditions, such as uterine fibroids, it is unknown whether endometrial disorders that lead to an impairment in normal menstruation should be considered to be primary endometrial disorders (disorders that are independent of the myometrial condition). Primary endometrial disorders can include: a reduced local hypoxia response with consequent interference with coordinated endometrial repair; an increased inflammatory response after progesterone withdrawal; a reduced haemostasis response due to an overactive endometrial fibrinolytic response; and a decrease in local vasoactive factors limiting vasoconstriction of the spiral arterioles, thereby contributing to excessive bleeding. An alternative, unproven, hypothesis is that the endometrium might behave in a manner consistent with a 'secondary endometrial disorder', in which changes occur in endometrial function as a consequence of the presence of a myometrial condition (for example, uterine fibroids or adenomyosis) ${ }^{138}$. oligomenorrhoea (an out of date term for infrequent menstruation), dysfunctional uterine bleeding and metrorrhagia (an out of date, confusing term for irregular menstruation) should be abandoned ${ }^{10}$. Consistency in terminology will facilitate data sharing, increase the validity of findings and improve patient care.

In wider society, there is also a need to address the discourse surrounding menstruation to prevent the harmful effects of menstrual stigma. In an online survey of 90,000 people $^{140}$ from over 190 countries, over 5,000 euphemisms ${ }^{141}$ for the word 'period' were identified. Beliefs about menstruation are affected by personal experience, society and culture. If shame and embarrassment prevail, women might not seek the medical care they require.

\section{Diagnosis}

Symptoms can be defined according to FIGO System 1. Evaluation for anaemia and iron deficiency should be undertaken, considering the high prevalence of iron deficiency and IDA in patients with HMB on a global scale, which so often is under-recognized and under-reported. Once bleeding has been confirmed to originate from the cervical canal or uterine cavity, a systematic assessment should be made to understand the cause or causes of AUB using FIGO System 2, the PALM-COEIN classification (FIG. 5; TABLE 1). This assessment will facilitate specific treatment of the underlying cause, personalizing management to improve effectiveness. If more than one cause of AUB is identified, this has implications for ongoing clinical management. Emphasis is generally placed on detailed history taking and examination as staffing levels, transportation to clinics and imaging modalities provide challenges for diagnosis in low-income to middle-income countries ${ }^{142}$.

To improve the diagnosis of the structural causes of AUB, the Morphological Uterus Sonographic Assessment group have detailed criteria for imaging the myometrium by transvaginal ultrasonography ${ }^{143,144}$, which is usually the most accessible imaging modality, although it is not $100 \%$ sensitive. MRI assessment is therefore indicated, for example, in patients who cannot tolerate or who decline transvaginal ultrasonography. MRI assessment might also be preferred to transvaginal ultrasonography in adolescents, patients with obesity, patients who have never been sexually active, patients with co-existing uterine fibroids and adenomyosis, or in patients with malignancy (such as sarcoma). Requirement for endometrial sampling in patients with AUB is based on risk factors for pre-malignant or malignant changes in the endometrium, including age, BMI, co-morbidities and genetic risk factors ${ }^{145,146}$.

\section{Personalizing treatments}

Effective management of AUB is required to treat and prevent anaemia and IDA and to improve social, emotional and material quality of life. Managing a patient with AUB depends upon the diagnosis (or diagnoses) and, therefore, needs to be tailored for safety and effectiveness alongside patient preferences, presence of co-morbidities, symptoms, impact on the quality of life, fertility desires, age and ongoing expectations. 


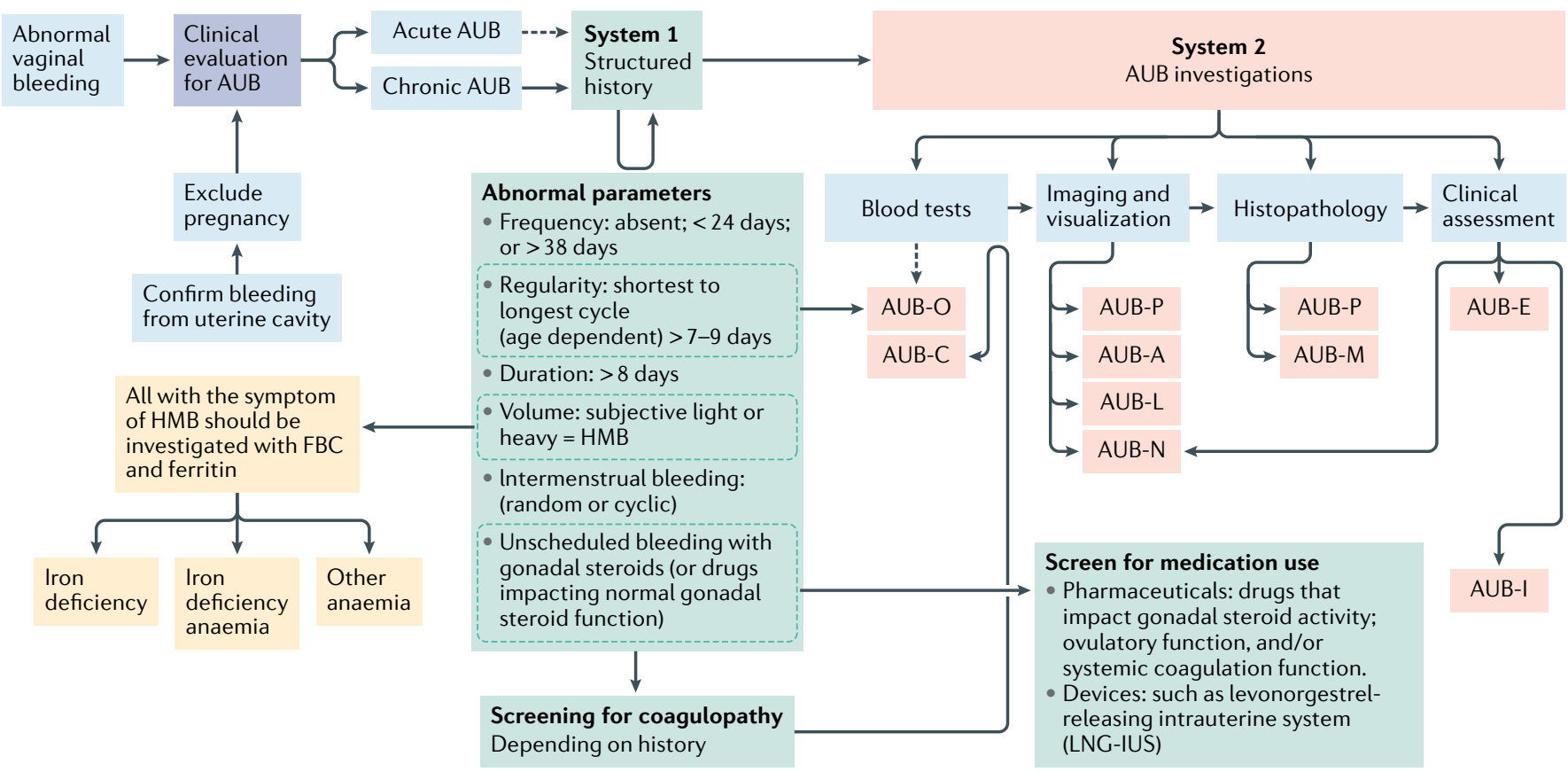

Fig. 5 | Diagnostic pathway for abnormal uterine bleeding, and iron deficiency and/or iron deficiency anaemia. On presentation with abnormal vaginal bleeding, the patient requires an initial assessment for pregnancy and to determine that the bleeding is coming from within the uterus, to confirm abnormal uterine bleeding (AUB). Such bleeding might either be acute or chronic (or acute on chronic). The time frame in which acute $A U B$ is investigated varies, as the initial clinical priority is to stem the acute haemorrhage. In those with chronic AUB, it is necessary to perform a thorough assessment to determine the cause or causes in order to direct management. These include understanding the precise AUB symptoms using the International Federation of Gynecology and Obstetrics (FIGO) AUB System 1 (green boxes) ${ }^{2}$ prior to undertaking the appropriate

investigations to identify the cause or causes of AUB using FIGO AUB System 2 classification (red boxes) ${ }^{2}$. Imaging and visualization can occur with one or a combination of transvaginal ultrasonography, sonohysterography, MRI and hysteroscopy. Of note, blood tests for AUB-C would follow a positive screen for coagulopathy. AUB-O is primarily diagnosed on the basis of the structured history and blood tests are generally not necessary, but measurement of serum levels of progesterone might be useful in selected instances. AUB-E is a primary disorder of endometrial haemostasis. The clinician makes this diagnosis if there is no other explanation found on the clinical assessment including history, physical examination, appropriate blood tests and uterine imaging. $\mathrm{HMB}$, heavy menstrual bleeding; FBC, full blood count.

It is debated in the literature whether menstruation is a physiologically necessary process ${ }^{36,97,138}$. Menstrual suppression is possible with exogenous sex steroids, as practised by, for example, athletes, military personnel or female astronauts ${ }^{147}$. In addition, people without menstrual abnormalities might desire a reduction in menstrual frequency or amenorrhoea on completion of their family ${ }^{148}$. However, a woman might also wish to undergo menstruation or retain her fertility and reproductive organs despite having finished her family, and these wishes should always be respected ${ }^{149}$. Menstrual suppression might not be a viable option for all women ${ }^{150}$.

An audit of HMB management in the UK by the Royal College of Obstetricians and Gynaecologists revealed that most treatments implemented for women with $\mathrm{HMB}$ were treating the symptom of excessive bleeding, rather than specific underlying causes ${ }^{151}$. Patients were often given a choice to try sex steroid therapies, but not all women respond to these agents in the same way, and a third of women felt they needed a hysterectomy to resolve $\mathrm{HMB}^{151}$. Hormone-based therapies increase exposure to sex steroid hormones, which could increase the burden of sex-steroid hormone-dependent conditions, for example, uterine fibroids or adenomyosis. This UK audit highlighted a problem that is most likely global, namely a lack of diagnosis for women presenting with the symptom of HMB. The artificial suppression of ovarian sex steroid hormones does not provide a panacea for women with menstrual abnormalities. Instead, there is a need for appropriate investigation, diagnosis and patient-specific management strategies in the treatment of $\mathrm{HMB}$.

Many of the current medical treatments for AUB are hormonal (such as the levonorgestrel-releasing intrauterine system and cyclical oral progestins) and can work well for those with a non-structural cause of AUB, for example, patients with coagulation disorders (AUB-C), such as von Willebrand disease. However, for individuals with structural causes of AUB, hormonal therapies might be less effective. For example, people with submucosal uterine fibroids (fibroids that deviate the endometrial cavity) might experience increased complications and decreased effectiveness when using an intrauterine hormone delivery system ${ }^{152}$. Furthermore, in all people using hormonal treatments there is a risk of adverse effects, such as bloating, mood changes and breast tenderness, which might prove unacceptable. Future development of bedside diagnostics to detect the specific underlying defect in those with non-structural AUB-E (such as excessive inflammation, decreased hypoxia or haemostasis defects) would facilitate personalized treatment to correct specific defects causing AUB. 
Surgical treatments can be life changing for people with structural causes of AUB (such as AUB-L or AUB-A) but can temporarily or permanently impair fertility, and therefore necessitate a careful informed discussion of the possible treatment choices. To date, hysterectomy remains the only guaranteed 'no bleed' option to prevent AUB for a patient, but this procedure has obvious implications for fertility, highlighting the need to develop more fertility-sparing medical and surgical interventions for AUB.

Gynaecological abnormalities, such as uterine fibroids and adenomyosis, can recur despite surgical treatment or medical adjuvant therapies ${ }^{153-156}$. As imaging modalities improve, the detection rates of myometrial conditions increase, and strategies to prevent co-morbidities related to these conditions could be developed that would result in earlier diagnosis. Disease-modifying agents are also needed in order to slow disease progression and defer a patient's need for surgical intervention.

Interestingly, women with uterine fibroids have been found to have more atherosclerotic cardiovascular risk factors than women without fibroids ${ }^{157}$. Women who had undergone a hysterectomy with ovarian conservation were subsequently found to have increased risks of cardiovascular and metabolic disease, including hyperlipidaemia and coronary artery disease, when compared with aged-matched women living in the same geographic location who had not undergone hysterectomy or oophorectomy ${ }^{158}$. These studies highlight that the decision to undergo a hysterectomy is not simple as the uterus might provide additional physiological functions beyond its role in reproduction. A holistic approach to a patient's health is important to consider when planning management for AUB. Uterine-sparing treatments, and especially new medical treatments, are therefore much needed.

\section{Factors affecting AUB}

Age and $A U B$. It remains unclear whether the endometrium ages across the reproductive lifespan in humans ${ }^{159,160}$. However, in mice, a blunted steroid hormonal response and reduced DNA methylation leads to defects in the decidualization phase with ageing which, in turn, negatively impacts reproductive outcomes ${ }^{161,162}$.

The risk of developing structural causes of AUB increases with advancing age ${ }^{163-167}$. Conversely, during the adolescent years, non-ovulatory cycles are more common, and adolescent girls are more likely to have a coagulopathy, such as von Willebrand disease, rather than a structural cause of AUB when compared with older women. The symptom of HMB in adolescent girls could lead to iron deficiency and IDA. These conditions can result in fatigue, headaches, low cognition affecting verbal learning and memory, poor school attendance and performance, decreased participation in sports and possibly symptoms of depressed mood and/or anxiety ${ }^{22}$.

Environment and AUB. Behaviour and the environment play an important role in a person's health. How this then affects changes at a genetic level is investigated in epigenetic studies. To date, however, there are no identifiable studies that have specifically investigated epigenetic changes in relation to AUB. Dietary factors, vitamin deficiencies, parity, caesarean section and drug exposure have all been reported to have an impact on the prevalence of the causes of AUB ${ }^{168-171}$. It is yet to be determined if SARS-CoV-2 infection has an impact on endometrial physiology and the experience of menstrual bleeding. Data derived during the COVID-19 pandemic have revealed substantial effects of SARS-CoV-2 infection on endothelial cell function and the immune system $^{172,173}$. In addition, the SARS-CoV-2 receptor, angiotensin-converting enzyme 2 , has been found to be present in the human ovary and uterus ${ }^{174,175}$. Therefore, it is plausible that COVID-19 might directly affect menstrual parameters in those infected, in addition to the expected effects on hypothalamic function with notable illness and/or stress.

Exercise can benefit women in regulating their menstrual cycles, as aerobic and strength training has been found to lead to improved insulin control ${ }^{176}$. Insulin receptors are expressed on the ovary and might influence the production of steroid hormones, including progesterone, thereby potentially impacting menstrual cycle control ${ }^{177}$. However, the efficacy of using exercise as a means to treat the symptom of HMB lacks robust evidence $^{178}$. Traditionally, intense exercise has been linked to hypothalamic amenorrhoea; however, elite athletes can also have AUB and $\mathrm{HMB}^{179,180}$.

$B M I$ and $A U B$. Menstrual disorders are more prevalent in women with overweight (BMI $25-30 \mathrm{~kg} / \mathrm{m}^{2}$ ) or obesity $\left(\mathrm{BMI} \geq 30 \mathrm{~kg} / \mathrm{m}^{2}\right)$ than in those with a BMI in the normal range (BMI $\left.20-25 \mathrm{~kg} / \mathrm{m}^{2}\right)^{181,182}$. Obesity is associated with elevated levels of oestrogen through peripheral conversion of androgens to oestrogen by aromatase in adipose tissue (particularly androstenedione) ${ }^{181}$. Women with obesity have lower levels of sex hormone binding globulin than women with a BMI in the normal range, which leads to higher levels of circulating or free testosterone. These hormonal changes can result in ovulatory dysfunction (AUB-O), which is infrequent ovulation that extends the proliferative phase of the menstrual cycle $^{182}$. This increased exposure to unopposed oestrogen could support excess proliferation within the endometrium and increase the likelihood of menstrual disturbances ${ }^{183}$.

Structural and non-structural causes of AUB have a higher prevalence in women with a high BMI $\left(\geq 30 \mathrm{~kg} / \mathrm{m}^{2}\right)$ than in those with a normal BMI $\left(20-25 \mathrm{~kg} / \mathrm{m}^{2}\right)^{164,169,184}$. Unfortunately, women with a high BMI have also been found to have less satisfaction with treatments for $\mathrm{AUB}$, such as the levonorgestrel-releasing intrauterine system $^{185}$. Women with a low BMI $\left(\leq 18.5 \mathrm{~kg} / \mathrm{m}^{2}\right)$, either due to diet restrictions or excessive exercise, are more likely to experience menstrual disturbances, particularly amenorrhoea, due to functional hypothalamic disorders, than women with a normal BMI. Leptin signalling might also contribute to menstrual disturbances in women with a low BMI, as it has been found that women with a low BMI have reduced synthesis of leptin compared with women with a normal BMI ${ }^{176,177,186,187}$. Elite athletes have an increased incidence of delayed menarche and 
primary amenorrhoea, specifically those participating in sports requiring leanness, for example, running, gymnastics and ballet ${ }^{188}$.

Ethnicity and menstrual research. The majority of research published in the literature related to ethnicity and its impact on the symptom of HMB focuses on conditions that cause AUB in black compared with white populations. There is a paucity of data on how ethnicity impacts the form and function of the female reproductive tract, and in the present context, the uterine endometrium and the menstrual cycle.

Myometrial conditions, such as uterine fibroids and adenomyosis are more prevalent in black women than in white women. Black women are also more likely to have both of these conditions compared with white women ${ }^{189,190}$. Black women are at greater risk of developing uterine fibroids at an earlier age, in larger size, greater number and with more severe symptoms

\section{Box 2 | New and emerging cross-discipline technologies being applied in} endometrial physiology research

\section{In vitro organoid technology and co-culture models}

Growing endometrial stromal and epithelial cells in vitro in co-culture provides a tool for studying cell to cell communication and endometrial functioning related to different clinical phenotypes ${ }^{194,206}$.

\section{Stem cell research}

Endometrial stem cell studies are revealing processes of endometrial regeneration after menstruation $^{121,127,207}$

\section{Microfluidics}

Via the integration of multiple so-called 'microphysiological systems' or 3D models representing part of the endometrium on a microscale, systemic effects that might influence menstruation can be investigated ${ }^{208}$.

\section{Menstrual fluid research}

This 'natural tissue biopsy' provides a potential source of information about the endometrium during normal and abnormal menstruation ${ }^{209}$.

\section{Bioinformatics}

Through the use of software, large complex datasets related to biological experiments of the endometrium can be analysed, potentially identifying pathways and mechanisms related to normal and abnormal functioning of the endometrium.

\section{Big data}

Large and varied clinical datasets related to women with abnormal uterine bleeding have the potential to elucidate patterns or subgroups to assist with targeting treatment groups.

\section{'-omics' and precision medicine}

For example, genomics, epigenomics, transcriptomics, proteomics and metabolomics have been applied to gain a deeper understanding of the physiological and pathological functioning of the endometrium ${ }^{79,210}$.

\section{Imaging}

It is hoped that the development of imaging capabilities within MRI and ultrasonography (for example, elastography) will provide non-invasive methods for investigation and potentially earlier diagnosis in vivo ${ }^{211,212}$.

\section{Artificial intelligence}

Machine learning has the potential to help in the early prediction and identification of women with possible causes of abnormal uterine bleeding, potentially improving future diagnosis and treatment.

\section{'FemTech'}

Devices, software and/or other technology related to women's health have the potential to improve diagnostic capability as well as increase awareness and knowledge surrounding menstrual health ${ }^{8}$. compared with white women ${ }^{165,191,192}$. This finding stresses the need for more genetically focused studies to further understand the ethnic differences in the progression of these conditions.

\section{Emerging technologies}

Human health and disease are ideally investigated in vivo; however, this is not always possible. This Review highlights key advances in endometrial physiology research using animal models of the menstrual cycle; for example, the use of non-human primate models or the simulated model of menses in mice. Models to study the endometrium in vitro have been developed in the past few years; for example, the use of endometrial epithelial cell organoid technology. These have the unique advantage of originating from human tissue whilst retaining the phenotype of the individual from whom they originated ${ }^{193-195}$.

There remain numerous unanswered questions within the field of endometrial physiology research. Emerging technologies will allow us to overcome some of the limitations of human studies and address these outstanding research questions ${ }^{36}$. These include, but are not limited to, the following: How does the presence of a myometrial condition, such as uterine fibroids or adenomyosis, impact the endometrium and lead to the abnormal bleeding phenotype of AUB? Is decidualization prior to menstruation a necessary event for coordinated menstrual loss and repair? Is it possible to characterize the interaction between innate immune cell traffic and the spiral arteriole vasculature within the endometrium and what is the role of the innate immune cell traffic in menstruation? Why does menstruation not result in tissue scarring? If we target key hormone-dependent pathways, would this help regulate menstruation in people with AUB? Is it possible to provide earlier, non-invasive diagnosis of all causes of AUB in a personalized manner, to appropriately treat millions of women around the world with this debilitating symptom? By addressing these key physiological and pathological questions we can implement preventative and therapeutic strategies to improve endometrial physiology.

New and emerging technologies (BOX 2) provide cross-discipline opportunities to offer insights into the biology of the endometrium in health and disease. These technologies have a potential role in diagnostics and could allow the monitoring of responses to treatment in clinical research. Additionally, they could provide avenues to elucidate the pathophysiology of conditions that cause AUB and identify novel targets for disease-modifying drug therapy ${ }^{196-198}$. These biomedical advances are being made alongside changes in policy and culture (for example, the introduction of free period products in Scotland and New Zealand) and an increasing discourse in society regarding menstruation ${ }^{199,200}$. Combined efforts to address menstrual shame, stigma and taboos, create menstrual-friendly policies and advance menstrual research will have considerable benefits for menstrual health as a whole. As an area of huge unmet clinical need, endometrial physiology research provides exciting opportunities for scientific advances whilst also having the potential to lead to a substantial positive impact on a global scale. 


\section{Conclusions}

AUB has a detrimental impact on those it affects and leads to considerable disease burden on a global scale. A large proportion of women with AUB globally also have either iron deficiency or IDA, which often is both under-recognized and under-reported. It is essential that we continue to delineate the physiology of the menstrual cycle using available and emerging technologies. Scientifically combating the knowledge gaps within the field of menstruation will translate to notable benefits across the globe for those who menstruate.

Published online 8 February 2022
1. National Collaborating Centre for Women's and Children's Health. Heavy menstrual bleeding (Ch. 3). https://www.nice.org.uk/guidance/ng88/evidence/ full-guideline-pdf-4782291810 (2007).

2. Munro, M. G. et al. The two FIGO systems for normal and abnormal uterine bleeding symptoms and classification of causes of abnormal uterine bleeding in the reproductive years: 2018 revisions. Int. J. Gynecol. Obstet. 143, 393-408 (2018). The latest guidance related to the classification system for the causes of abnormal uterine bleeding with key updates.

3. Royal College of Obstetricians and Cynaecologists. National heavy menstrual bleeding audit final Report (Ch. 1). https://www.rcog.org.uk/globalassets/ documents/guidelines/research--audit/national_hmb audit_final_report_july_2014.pdf (2014)

4. Schoep, M. E., Nieboer, T. E., van der Zanden, M., Braat, D. D. M. \& Nap, A. W. The impact of menstrua symptoms on everyday life: a survey among 42,879 women. Am. J. Obstet. Gynecol. 220, 569.e1-569.e7 (2019).

5. Eaton, S. B. et al. Women's reproductive cancers in evolutionary context. Q. Rev. Biol. 69, 353-367 (1994).

6. Weaver, J. M., Schofield, T. J. \& Papp, L. M Breastfeeding duration predicts greater maternal sensitivity over the next decade. Dev. Psychol. 54 220-227 (2018)

7. Short, R. V. The evolution of human reproduction Proc. R. Soc. Lond. B. Biol. Sci. 195, 3-24 (1976).

8. Hennegan, J. et al. Menstrual health: a definition for policy, practice, and research. Sex. Reprod. Health Matters 29, 1911618 (2021).

A key article defining and discussing menstrual health and its importance.

9. Bobel, C. et al. The Palgrave Handbook of Critical Menstruation Studies (Springer, 2020).

10. Munro, M. G., Critchley, H. O., Broder, M. S. \& Fraser, I. S., FIGO Working Group on Menstrual Disorders. FIGO classification system (PALM-COEIN) for causes of abnormal uterine bleeding in nongravid women of reproductive age. Int. J. Gynaecol. Obstet 113, 3-13 (2011).

11. National Institute for Health and Care Excellence. Heavy menstrual bleeding: assessment and management. NICE guideline NG88. https://www. nice. org.uk/guidance/ng88/resources/heavy-menstrualbleeding-assessment-and-management-pdf1837701412549 (2018).

12. Peric, H. \& Fraser, I. S. The symptomatology of adenomyosis. Best. Pract. Res. Clin. Obstet. Gynaecol. 20, 547-555 (2006)

13. Munro, M. G., Critchley, H. \& Fraser, I. S. Research and clinical management for women with abnormal uterine bleeding in the reproductive years: more than PALM-COEIN. BJOG 124, 185-189 (2017).

14. Fraser, I. S., Langham, S. \& Uhl-Hochgraeber, K Health-related quality of life and economic burden of abnormal uterine bleeding. Expert Rev. Obstet. Gynecol. 4, 179-189 (2009). A thorough summary on the burden and impact of abnormal uterine bleeding.

15. Shapley, M., Jordan, K. \& Croft, P. R. An epidemiologica survey of symptoms of menstrual loss in the community. Br. J Gen Pract 54, 359-363 (2004).

16. Hallberg, L. \& Nilsson, L. Determination of menstrual blood loss. Scand. J. Clin. Lab. Invest. 16, 244-248 (1964).

17. Bhattacharya, S. et al. Hysterectomy, endometrial ablation and Mirena $(\mathrm{R})$ for heavy menstrual bleeding. a systematic review of clinical effectiveness and cost-effectiveness analysis. Health Technol. Assess. 15, 1-252 (2011).

18. Royal College of Obstetricians and Gynaecologists. National heavy menstrual bleeding audit: final report (Executive Summary). https://www.rcog.org.uk/ globalassets/documents/guidelines/research--audit/ national_hmb_audit_final_report_july_2014.pdf (2014).
19. World Health Organization. The global prevalence of anaemia in 2011. https://apps.who.int/iris/bitstream/ handle/10665/177094/9789241564960 eng.pdf;jsessionid=9D31 A00D99F33BC96D3367 FCA3D5F784? sequence $=1$ (2015).

20. Stoltzfus, R. J., Mullany, L. \& Black, R. E. in Comparative quantification of health risks: global and regional burden of disease attributable to selected major risk factors Ch. 3 (eds Ezzati, M., Lopez, A. D. Rodgers, A. \& Murray, C. J. L.) 163-209 (WHO, 2004)

21. Friedman, A. J. et al. Iron deficiency anemia in women across the life span. J. Women's Health 21, 1282-1289 (2012).

22. Camaschella C. Iron-deficiency anemia. N. Engl. J. Med. 372, 1832-1843 (2015).

An in-depth overview on the importance and impact of iron deficiency and iron deficiency anaemia.

23. Munro, M. G., FIGO Committee on Menstrual Disorders. Abnormal uterine bleeding: a well-travelled path to iron deficiency and anemia. Int. J. Gynaecol. Obstet. 150, 275-277 (2020)

24. Percy, L., Mansour, D. \& Fraser, I. Iron deficiency and iron deficiency anaemia in women. Best. Pract. Res. Clin. Obstet. Gynaecol. 40, 55-67 (2017).

25. Liu, Z., Doan, Q. V., Blumenthal, P. \& Dubois, R. W. A systematic review evaluating health-related quality of life, work impairment, and health-care costs and utilization in abnormal uterine bleeding. Value Health 10, 183-194 (2007)

26. Wang, Y. X. et al. Menstrual cycle regularity and length across the reproductive lifespan and risk of premature mortality: prospective cohort study. BMJ 371, m3464 (2020).

27. Coulter, A., Peto, V. $\&$ Jenkinson, C. Quality of life and patient satisfaction following treatment for menorrhagia. Fam. Pract. 11, 394-401 (1994).

28. Office for National Statistics. Birth characteristics in England and Wales: 2017. https://

www.ons.gov.uk/peoplepopulationandcommunity/ birthsdeathsandmarriages/livebirths/bulletins/ birthcharacteristicsinenglandandwales/2017 (2019).

29. Fortin, C. N., Hur, C., Radeva, M. \& Falcone, T. Effects of myomas and myomectomy on assisted reproductive technology outcomes. J. Gynecol. Obstet. Hum. Reprod. 48, 751-755 (2019).

30. Cardozo, E. R. et al. The estimated annual cost of uterine leiomyomata in the United States. Am. J. Obstet. Gynecol. 206, 211.e1-211.e9 (2012).

31. Rice, J. P., Kay, H. H. \& Mahony, B. S. The clinical significance of uterine leiomyomas in pregnancy. Am. J. Obstet. Gynecol. 160, 1212-1216 (1989).

32. Bofill Rodriguez, M., Lethaby, A., Farquhar, C. \& Duffy, J. M. Interventions commonly available during pandemics for heavy menstrual bleeding: an overview of Cochrane Reviews. Cochrane Database Syst. Rev. 7 CD013651 (2020)

33. Royal College of Obstetricians \& Gynaecologists, British Society for Gynaecological Endoscopy \& British Gynaecological Cancer Society. Joint RCOG, BSGE and BCCS guidance for the management of abnormal uterine bleeding in the evolving Coronavirus (COVID-19) pandemic. https://www.rcog.org.uk/globalassets/ documents/guidelines/2020-05-21-joint-rcog-bsgebgcs-guidance-for-management-of-abnormal-uterinebleeding-aub-in-the-evolving-coronavirus-covid-19pandemic-updated-final-180520.pdf (2020).

34. Jacob, C. M. et al. Building resilient societies after COVID-19: the case for investing in maternal, neonatal, and child health. Lancet Public Health $\mathbf{5}$, e624-e627 (2020).

35. Chodankar, R. \& Critchley, H. O. D. Biomarkers in abnormal uterine bleeding. Biol. Reprod. 101, 1155-1166 (2019).

36. Critchley, H. O. D., Maybin, J. A., Armstrong, G. M. \& Williams, A. R. W. Physiology of the endometrium and regulation of menstruation. Physiol. Rev. 100, 1149-1179 (2020)

An in-depth review on the physiology of the endometrium related to menstruation.
37. Chang, J., Siebert, J. W., Schendel, S. A., Press, B. H. \& Longaker, M. T. Scarless wound healing: implications for the aesthetic surgeon. Aesthetic Plast. Surg. 19, 237-241 (1995).

38. Somasundaram, K. \& Prathap, K. The effect of exclusion of amniotic fluid on intra-uterine healing of skin wounds in rabbit foetuses. J. Pathol. 107, 127-130 (1972).

39. Salamonsen, L A \& Lathbury, L. J. Endometrial leukocytes and menstruation. Hum. Reprod. Update 6, 16-27 (2000)

40. Jeziorska, M., Salamonsen, L. A. \& Woolley, D. E. Mast cell and eosinophil distribution and activation in human endometrium throughout the menstrual cycle. Biol. Reprod. 53, 312-320 (1995).

41. Armstrong, G. M. et al. Endometrial apoptosis and neutrophil infiltration during menstruation exhibits spatial and temporal dynamics that are recapitulated in a mouse model. Sci. Rep. 7, 17416 (2017).

42. Patel, B. et al. Role of nuclear progesterone receptor isoforms in uterine pathophysiology. Hum. Reprod. Update 21, 155-173 (2015).

43. Faculty of Sexual \& Reproductive Healthcare. FSRH Clinical guideline: problematic bleeding with hormonal contraception (July 2015). https://www. fsrh.org/standards-and-guidance/documents/ ceuguidanceproblematicbleedinghormonalcontraception/ (2015).

44. Chodankar, R. \& Critchley, H. O. Abnormal uterine bleeding (including PALM COEIN classification) Obstet. Gynaecol. Reprod. Med. 29, 98-104 (2019).

45. Abdel-Aleem, H., d'Arcangues, C., Vogelsong, K. M. Gaffield, M. L. \& Gülmezoglu, A. M. Treatment of vaginal bleeding irregularities induced by progestin only contraceptives. Cochrane Database Syst. Rev. 10, CD003449 (2013)

46. Kowalik, M. K., Rekawiecki, R. \& Kotwica, J. The putative roles of nuclear and membrane-bound progesterone receptors in the female reproductive tract. Reprod. Biol. 13, 279-289 (2013).

47. Young, S. L. \& Lessey, B. A. Progesterone function in human endometrium: clinical perspectives. Semin. Reprod. Med. 28, 5-16 (2010).

A review discussing the importance of progesterone and its role in endometrial function.

48. Wagenfeld, A., Saunders, P. T., Whitaker, L. \& Critchley, H. O. Selective progesterone receptor modulators (SPRMs): progesterone receptor action, mode of action on the endometrium and treatment options in gynecological therapies. Expert. Opin. Ther Targets 20, 1045-1054 (2016).

49. Li, X. \& O'Malley, B. W. Unfolding the action of progesterone receptors. J. Biol. Chem. 278, 39261-39264 (2003).

50. Critchley, H. O. D. \& Chodankar, R. R. 90 years of progesterone: selective progesterone receptor modulators in gynaecological therapies. J. Mol. Endocrinol. 65, T15-T33 (2020).

51. Williams, A. R., Bergeron, C., Barlow, D. H. \& Ferenczy, A. Endometrial morphology after treatment of uterine fibroids with the selective progesterone receptor modulator, ulipristal acetate. Int. J. Gynecol. Pathol. 31, 556-569 (2012).

52. Chodankar, R. R. et al. The endometrial response to modulation of ligand-progesterone receptor pathways is reversible. Fertil. Steril. 116, 882-895 (2021).

53. Gibson, D. A. \& Saunders, P. T. Estrogen dependent signaling in reproductive tissues - a role for estrogen receptors and estrogen related receptors. Mol. Cell Endocrinol. 348, 361-372 (2012).

54. Critchley, H. O. et al. Estrogen receptor $\beta$, but not estrogen receptor $\alpha$, is present in the vascular endothelium of the human and nonhuman primate endometrium. J. Clin. Endocrinol. Metab. 86, 1370-1378 (2001).

55. Couse, J. F., Lindzey, J., Grandien, K., Gustafsson, J. A $\&$ Korach, K. S. Tissue distribution and quantitative analysis of estrogen receptor- $\alpha(E R \alpha)$ and estrogen receptor- $\beta(E R \beta)$ messenger ribonucleic acid in the 
wild-type and ERa-knockout mouse. Endocrinology 138, 4613-4621 (1997).

56. Pettersson, K. \& Gustafsson, J. Å. Role of estrogen receptor beta in estrogen action. Annu. Rev. Physiol. 63, 165-192 (2001).

57. Hewitt, S. C., Winuthayanon, W. \& Korach, K. S. What's new in estrogen receptor action in the female reproductive tract. J. Mol. Endocrinol. 56, R55-R71 (2016).

58. Critchley, H. O. \& Saunders, P. T. Hormone receptor dynamics in a receptive human endometrium. Reprod. Sci. 16, 191-199 (2009).

59. Gibson, D. A., Simitsidellis, I., Collins, F. \& Saunders, P. T. K. Endometrial intracrinology: oestrogens, androgens and endometrial disorders. Int. J. Mol. Sci. 19, 3276 (2018).

An in-depth and important review of endometrial intracrinology.

60. Labrie, F. et al. The key role of 17 beta-hydroxysteroid dehydrogenases in sex steroid biology. Steroids 62,148-158 (1997).

61. Guttinger, A. ¿ Critchley, H. O. Endometrial effects of intrauterine levonorgestrel. Contraception 75, S93-S98 (2007)

62. Konings, G. et al. Intracrine regulation of estrogen and other sex steroid levels in endometrium and non-gynecological tissues; pathology, physiology, and drug discovery. Front. Pharmacol. 9, 940 (2018).

63. Simitsidellis, I., Saunders, P. T. K. \& Gibson, D. A. Androgens and endometrium: new insights and new targets. Mol. Cell Endocrinol. 465, 48-60 (2018).

64. Huhtinen, K. et al. Intra-tissue steroid profiling indicates differential progesterone and testosterone metabolism in the endometrium and endometriosis lesions. J. Clin. Endocrinol. Metab. 99, E2188-E2197 (2014).

65. McDonald, S. E., Henderson, T. A., Gomez-Sanchez, C. E., Critchley, H. O. \& Mason, J. I. $11 \beta$-Hydroxysteroid dehydrogenases in human endometrium. Mol. Cell Endocrinol. 248, 72-78 (2006)

66. Milne, S. A. et al. Leukocyte populations and steroid receptor expression in human first-trimester decidua; regulation by antiprogestin and prostaglandin $\mathrm{E}$ analog. J. Clin. Endocrinol. Metab. 90, 4315-4321 (2005).

67. Marshall, E. et al. In silico analysis identifies a novel role for androgens in the regulation of human endometrial apoptosis. J. Clin. Endocrinol. Metab. 96 E1746-E1755 (2011)

68. Cousins, F. L. et al. Androgens regulate scarless repair of the endometrial "wound" in a mouse model of menstruation. FASEB J.30, 2802-2811 (2016).

69. Gibson, D. A., Simitsidellis, I., Cousins, F. L. Critchley, H. O. \& Saunders, P. T. Intracrine androgens enhance decidualization and modulate expression of human endometrial receptivity genes. Sci. Rep. 6 19970 (2016).

70. Garry, R., Hart, R., Karthigasu, K. A. \& Burke, C. A re-appraisal of the morphological changes within the endometrium during menstruation: a hysteroscopic, histological and scanning electron microscopic study. Hum. Reprod. 24, 1393-1401 (2009). Key research highlighting the repair and regeneration processes during menstruation

71. Burris, T. P. et al. Nuclear receptors and their selective pharmacologic modulators. Pharmacol. Rev. 65 710-778 (2013)

72. Henderson, T. A., Saunders, P. T., Moffett-King, A., Groome, N. P. \& Critchley, H. O. Steroid receptor expression in uterine natural killer cells. J. Clin. Endocrinol. Metab. 88, 440-449 (2003).

73. Logie, J. J. et al. Glucocorticoid-mediated inhibition of angiogenic changes in human endothelial cells is not caused by reductions in cell proliferation or migration. PLOS ONE 5, e 14476 (2010).

74. Edwards, C. R., Benediktsson, R., Lindsay, R. S. \& Seckl, J. R. 11 $\beta$-Hydroxysteroid dehydrogenases: key enzymes in determining tissue-specific glucocorticoid effects. Steroids 61, 263-269 (1996).

75. Rae, M. et al. Cortisol inactivation by $11 \beta$-hydroxysteroid dehydrogenase- 2 may enhance endometrial angiogenesis via reduced thrombospondin- 1 in heavy menstruation. J. Clin. Endocrinol. Metab. 94 1443-1450 (2009)

76. Warner, P. et al. Low-dose dexamethasone as a treatment for women with heavy menstrual bleeding protocol for response-adaptive randomised placebo-controlled dose-finding parallel group trial (DexFEM). BMJ Open 5, e006837 (2015).

77. Warner, P. et al. Low dose dexamethasone as treatment for women with heavy menstrual bleeding: a response-adaptive randomised placebo-controlled dose-finding parallel group trial (DexFEM).

EBioMedicine 69, 103434 (2021).

78. Gellersen, B. \& Brosens, J. J. Cyclic decidualization of the human endometrium in reproductive health and failure. Endocr. Rev. 35, 851-905 (2014).

A highly descriptive and detailed review about the processes surrounding decidualization in the endometrium

79. Wang, W. et al. Single-cell transcriptomic atlas of the human endometrium during the menstrual cycle. Nat. Med. 26, 1644-1653 (2020)

80. Altmae, S. et al. Meta-signature of human endometrial receptivity: a meta-analysis and validation study of transcriptomic biomarkers. Sci. Rep. 7, 10077 (2017).

81. Patel, B. G., Rudnicki, M., Yu, J., Shu, Y. \& Taylor, R. N. Progesterone resistance in endometriosis: origins, consequences and interventions. Acta Obstet. Gynecol. Scand. 96, 623-632 (2017).

82. Mehasseb, M. K. et al. Estrogen and progesterone receptor isoform distribution through the menstrual cycle in uteri with and without adenomyosis. Fertil. Steril. 95, 2228-2235.e1 (2011).

83. Whitaker, L. H. et al. Selective progesterone receptor modulator (SPRM) ulipristal acetate (UPA) and its effects on the human endometrium. Hum. Reprod. 32 531-543 (2017)

84. Taylor, H. S., Arici, A., Olive, D. \& Igarashi, P. HOXA10 is expressed in response to sex steroids at the time of implantation in the human endometrium. J. Clin. Invest. 101, 1379-1384 (1998).

85. Kelly, R. W., King, A. E. \& Critchley, H. O. Cytokine control in human endometrium. Reproduction 121 3-19 (2001)

86. Evans, J. \& Salamonsen, L. A. Decidualized human endometrial stromal cells are sensors of hormone withdrawal in the menstrual inflammatory cascade. Biol. Reprod. 90, 14 (2014).

87. Chase, A. J., Bond, M., Crook, M. F. \& Newby, A. C. Role of nuclear factor-kB activation in metalloproteinase-1, -3 , and -9 secretion by human macrophages in vitro and rabbit foam cells produced in vivo. Arterioscler. Thromb. Vasc. Biol. 22, 765-771 (2002).

88. Critchley, H. O., Kelly, R. W., Brenner, R. M. \& Baird, D. T. The endocrinology of menstruation-a role for the immune system. Clin. Endocrinol. 55, 701-710 (2001).

89. Marbaix, E. et al. Menstrual breakdown of human endometrium can be mimicked in vitro and is selectively and reversibly blocked by inhibitors of matrix metalloproteinases. Proc. Natl Acad. Sci. USA 93, 9120-9125 (1996)

90. Wang, Q. et al. A critical period of progesterone withdrawal precedes endometrial breakdown and shedding in mouse menstrual-like model. Hum. Reprod. 28, 1670-1678 (2013).

91. Slayden, O. D. \& Brenner, R. M. A critical period of progesterone withdrawal precedes menstruation in macaques. Reprod. Biol. Endocrinol. 4, S6 (2006).

92. Brasted, M., White, C. A., Kennedy, T. G. \& Salamonsen, L. A. Mimicking the events of menstruation in the murine uterus. Biol. Reprod. 69 1273-1280 (2003).

Key research describing the mouse model of simulated menses, including decidualization, endometrial shedding and endometrial repair highlighting how this model can mimic the events of human menstruation.

93. Nayak, N. R. et al. Progesterone withdrawal up-regulates vascular endothelial growth factor receptor type 2 in the superficial zone stroma of the human and macaque endometrium: potential relevance to menstruation. J. Clin. Endocrinol. Metab. 85, 3442-3452 (2000)

94. Martínez-Aguilar, R., Kershaw, L. E., Reavey, J. J., Critchley, H. O. \& Maybin, J. A. Hypoxia and reproductive health: the presence and role of hypoxia in the endometrium. Reproduction 161, F1-F17 (2021).

95. Maybin, J. A., Critchley, H. O. \& Jabbour, H. N. Inflammatory pathways in endometrial disorders. Mol. Cell Endocrinol. 335, 42-51 (2011).

96. Maybin, J. \& Critchley, H. Repair and regeneration of the human endometrium. Expert Rev. Obstet Gynecol. 4, 283-298 (2009).

97. Maybin, J. A. \& Critchley, H. O. Menstrual physiology: implications for endometrial pathology and beyond. Hum. Reprod. Update 21, 748-761 (2015).

98. Mints, M. et al. Wall discontinuities and increased expression of vascular endothelial growth factor-A and vascular endothelial growth factor receptors 1 and 2 in endometrial blood vessels of women with menorrhagia. Fertil. Steril. 88, 691-697 (2007).

99. Abberton, K. M., Taylor, N. H., Healy, D. L. \& Rogers, P. A. Vascular smooth muscle cell proliferation in arterioles of the human endometrium. Hum. Reprod. 14, 1072-1079 (1999).

100. Abberton, K. M., Healy, D. \& Rogers, P. A. Smooth muscle alpha actin and myosin heavy chain expression in the vascular smooth muscle cells surrounding human endometrial arterioles. Hum. Reprod. 14 3095-3100 (1999).

101. Lu, Q. et al. Transforming growth factor (TGF) $\beta$ and endometrial vascular maturation. Front. Cell Dev. Biol. 9, 640065 (2021).

102. Maybin, J. A., Boswell, L., Young, V. J., Duncan, W. C. $\&$ Critchley, H. O. D. Reduced transforming growth factor- $\beta$ activity in the endometrium of women with heavy menstrual bleeding. J. Clin. Endocrinol. Metab. 102, 1299-1308 (2017).

103. Markee, J. E. Menstruation in intraocular endometrial transplants in the rhesus monkey Part I. Observations on normal menstrual cycles. Contrib. Embryol. 28, 223-308 (1940).

104. Fan, X. et al. VEGF blockade inhibits angiogenesis and reepithelialization of endometrium. FASEB J. 22, 3571-3580 (2008).

105. Maybin, J. A. et al. Hypoxia and hypoxia inducible factor- $1 \alpha$ are required for normal endometrial repair during menstruation. Nat. Commun. 9, 295 (2018). Key research highlighting the importance of hypoxia and the role of HIF $1 \alpha$ in the endometrium.

106. Cousins, F. L., Murray, A. A., Scanlon, J. P. \& Saunders, P. T. Hypoxyprobe reveals dynamic spatial and temporal changes in hypoxia in a mouse model of endometrial breakdown and repair. BMC Res. Notes 9, 30 (2016).

107. Semenza, G. L. HIF-1: mediator of physiological and pathophysiological responses to hypoxia. J. Appl. Physiol. 88, 1474-1480 (2000).

108. Schodel, J. et al. High-resolution genome-wide mapping of HIF-binding sites by ChIP-seq. Blood 117 e207-e217 (2011)

109. Critchley, H. O. et al. Hypoxia-inducible factor- $1 \alpha$ expression in human endometrium and its regulation by prostaglandin E-series prostanoid receptor 2 (EP2). Endocrinology 147, 744-753 (2006).

110. Green, D. Coagulation cascade. Hemodial. Int. 10, S2-S4 (2006)

111. Baker, D. J., Grimes, E. A. \& Hopwood, A. J. D-dimer assays for the identification of menstrual blood. Forensic Sci. Int. 212, 210-214 (2011).

112. Shankar, M., Lee, C. A., Sabin, C. A., Economides, D. L. $\&$ Kadir, R. A. von Willebrand disease in women with menorrhagia: a systematic review. BJOG 111 734-740 (2004)

113. Sandberg, T., Eriksson, P., Gustavsson, B. \& Casslen, B. Differential regulation of the plasminogen activator inhibitor-1 (PAl-1) gene expression by growth factors and progesterone in human endometrial stromal cells. Mol. Hum. Reprod. 3 781-787 (1997).

114. Gleeson, N., Devitt, M., Sheppard, B. L. \& Bonnar, J. Endometrial fibrinolytic enzymes in women with normal menstruation and dysfunctional uterine bleeding. Br. J. Obstet. Gynaecol. 100, 768-771 (1993).

115. Nordengren, J. et al. Differential localization and expression of urokinase plasminogen activator (UPA), its receptor (UPAR), and its inhibitor (PAI-1) mRNA and protein in endometrial tissue during the menstrual cycle. Mol. Hum. Reprod. 10, 655-663 (2004).

116. Bryant-Smith, A. C., Lethaby, A., Farquhar, C. \& Hickey, M. Antifibrinolytics for heavy menstrual bleeding. Cochrane Database Syst. Rev. 4, CD000249 (2018).

117. Ludwig, H. \& Spornitz, U. M. Microarchitecture of the human endometrium by scanning electron microscopy: menstrual desquamation and remodeling. Ann. N. Y. Acad. Sci. 622, 28-46 (1991).

118. Ghosh, A. et al. In vivo cell fate tracing provides no evidence for mesenchymal to epithelial transition in adult fallopian tube and uterus. Cell Rep. 31, 107631 (2020).

119. Chan, R. W. \& Gargett, C. E. Identification of label-retaining cells in mouse endometrium. Stem Cell 24, 1529-1538 (2006).

120. Taylor, H. S. Endometrial cells derived from dono stem cells in bone marrow transplant recipients. JAMA 292, 81-85 (2004). 
121. Gargett, C. E., Schwab, K. E. \& Deane, J. A Endometrial stem/progenitor cells: the first 10 years. Hum. Reprod. Update 22, 137-163 (2016).

122. Chan, R. W., Schwab, K. E. \& Gargett, C. E. Clonogenicity of human endometrial epithelial and stromal cells. Biol. Reprod. 70, 1738-1750 (2004).

123. Tempest, N., Baker, A. M., Wright, N. A. \& Hapangama, D. K. Does human endometrial LGR5 gene expression suggest the existence of another hormonally regulated epithelial stem cell niche? Hum. Reprod. 33, 1052-1062 (2018).

124. Tempest, N. et al. Histological 3D reconstruction and in vivo lineage tracing of the human endometrium. J. Pathol. 251, 440-451 (2020).

125. Ong, Y. R. et al. Bone marrow stem cells do not contribute to endometrial cell lineages in chimeric mouse models. Stem Cell 36, 91-102 (2018).

126. Deane, J. A., Ong, Y., Cousins, F. L. \& Gargett, C. E. Bone marrow-derived endometrial cells: transdifferentiation or misidentification? Hum. Reprod. Update 25, 272-274 (2019).

127. Santamaria, X., Mas, A., Cervelló, I., Taylor, H. \& Simon, C. Uterine stem cells: from basic research to advanced cell therapies. Hum. Reprod. Update $\mathbf{2 4}$, 673-693 (2018)

A review covering the involvement of stem cells in endometrial physiology as well as the uses of stem cell therapy in relation to uterine disease.

128. Arrowsmith, S., Robinson, H., Noble, K. \& Wray, S What do we know about what happens to myometrial function as women age? J. Muscle Res. Cell Motil. 33 209-217 (2012)

129. Aguilar, H. N. \& Mitchell, B. F. Physiological pathways and molecular mechanisms regulating uterine contractility. Hum. Reprod. Update 16, 725-744 (2010)

130. Islam, M. S., Akhtar, M. M. \& Segars, J. H. Vitamin D deficiency and uterine fibroids: an opportunity for treatment or prevention? Fertil. Steril. 115, 1175-1176 (2021).

131. Bulun S. E. Uterine fibroids. N. Engl. J. Med. 369 1344-1355 (2013)

132. Vannuccini, S. et al. Pathogenesis of adenomyosis: an update on molecular mechanisms. Reprod. Biomed. Online 35, 592-601 (2017)

133. Benagiano, G., Habiba, M. \& Brosens, I. The pathophysiology of uterine adenomyosis: an update. Fertil. Steril. 98, 572-579 (2012).

134. Leyendecker, G., Wildt, L. \& Mall, G. The pathophysiology of endometriosis and adenomyosis: tissue injury and repair. Arch. Gynecol. Obstet. 280 529-538 (2009)

135. Guo, S. W. The pathogenesis of adenomyosis vis-à-vis endometriosis. J. Clin. Med. 9, 485 (2020).

136. Liu, X., Shen, M., Qi, Q., Zhang, H. \& Guo, S. W. Corroborating evidence for platelet-induced epithelial-mesenchymal transition and fibroblast-tomyofibroblast transdifferentiation in the development of adenomyosis. Hum. Reprod. 31, 734-749 (2016).

137. Guo, S. W., Mao, X., Ma, Q. \& Liu, X. Dysmenorrhea and its severity are associated with increased uterine contractility and overexpression of oxytocin receptor (OTR) in women with symptomatic adenomyosis. Fertil. Steril. 99, 231-240 (2013).

138. Critchley, H. O. D. et al. Menstruation: science and society. Am. J. Obstet. Gynecol. 223, 624-664 (2020).

Provides a comprehensive summary of endometrial physiology as well as the methods used to investigate the endometrium

139. Woolcock, J. G., Critchley, H. O., Munro, M. G., Broder, M. S. \& Fraser, I. S. Review of the confusion in current and historical terminology and definitions for disturbances of menstrual bleeding. Fertil. Steril. 90, 2269-2280 (2008)

140. Clue. Talking about periods: an international investigation findings. https://helloclue.com/articles/ culture/talking-about-periods-an-internationalinvestigation-findings (2016)

141. Clue. Top euphemisms for "period" by language. helloclue.com https://helloclue.com/articles/culture/ top-euphemisms-for-period-by-language (2016).

142. Haththotuwa, R et al. Management of abnormal uterine bleeding in low- and high-resource settings: consideration of cultural issues. Semin. Reprod. Med. 29, 446-458 (2011).

143. Van den Bosch, T. et al. Terms, definitions and measurements to describe sonographic features of myometrium and uterine masses: a consensus opinion from the Morphological Uterus Sonographic Assessment (MUSA) group. Ultrasound Obstet. Gynecol. 46, 284-298 (2015).
144. Van den Bosch, T. et al. Sonographic classification and reporting system for diagnosing adenomyosis. Ultrasound Obstet. Gynecol. 53, 576-582 (2019).

145. Committee on Practice Bulletins-Gynecology. Practice bulletin no. 128: diagnosis of abnormal uterine bleeding in reproductive-aged women. Obstet. Gynecol. 120, 197-206 (2012).

146. Royal College of Obstetricians and Gynaecologists. Advice for Heavy Menstrual Bleeding (HMB) Services and Commissioners. Chapter 1. https://www.rcog.org. uk/globalassets/documents/guidelines/research--audit advice-for-hmb-services-booklet.pdf (2014)

147. Jain, V. \& Wotring, V. E. Medically induced amenorrhea in female astronauts. NPJ Microgravity 2, 16008 (2016)

148. Ferrero, S. et al. What is the desired menstrual frequency of women without menstruation-related symptoms? Contraception 73, 537-541 (2006)

149. Thomas, S. L. \& Ellertson, C. Nuisance or natural and healthy: should monthly menstruation be optional for women? Lancet 355, 922-924 (2000).

150. Chen, B. A et al. Bleeding changes after levonorgestrel 52-mg intrauterine system insertion for contraception in women with self-reported heavy menstrual bleeding. Am. J. Obstet. Gynecol. 222, S888.e1-S888.e6 (2020)

151. Royal College of Obstetricians and Gynaecologists. National Heavy Menstrual Bleeding Audit: Final Report (Ch. 4). https://www.rcog.org.uk/globalassets/ documents/guidelines/research--audit/national_hmb_ audit_final_report_july_2014.pdf (2014).

152. Ikomi, A. \& Pepra, E. F. Efficacy of the levonorgestrel intrauterine system in treating menorrhagia: actualities and ambiguities. J. Fam. Plann. Reprod. Health Care 28, 99-100 (2002)

153. Li, Q. et al. The efficacy of medical treatment for adenomyosis after adenomyomectomy. J. Obstet. Gynaecol. Res. 46, 2092-2099 (2020).

154. Mikos, T., Lioupis, M., Anthoulakis, C. \& Grimbizis, G. F. The outcome of fertility-sparing and nonfertilitysparing surgery for the treatment of adenomyosis. a systematic review and meta-analysis. J. Minim. Invasive Gynecol. 27, 309-331.e3 (2020).

155. Radosa, M. P. et al. Long-term risk of fibroid recurrence after laparoscopic myomectomy. Eur. J. Obstet. Gynecol. Reprod. Biol. 180, 35-39 (2014).

156. American College of Obstetricians Gynecologists. ACOG practice bulletin. Alternatives to hysterectomy in the management of leiomyomas. Obstet. Gynecol. 112, 387-400 (2008)

157. Laughlin-Tommaso, S. K. et al. Uterine fibroids and the risk of cardiovascular disease in the coronary artery risk development in Young Adult Women's Study. J. Womens Health 28, 46-52 (2019).

158. Laughlin-Tommaso, S. K. et al. Cardiovascular and metabolic morbidity after hysterectomy with ovarian conservation: a cohort study. Menopause 25 483-492 (2018).

159. Batista, M. C. et al. Effects of aging on menstrual cycle hormones and endometrial maturation. Fertil. Steril. 64, 492-499 (1995)

160. Noci, I. et al. I. Aging of the human endometrium: a basic morphological and immunohistochemical study. Eur. J. Obstet. Gynecol. Reprod. Biol. 63 , 181-185 (1995)

161. Woods, L. et al. Decidualisation and placentation defects are a major cause of age-related reproductive decline. Nat. Commun. 8, 352 (2017).

162. Woods, L. et al. Epigenetic changes occur at decidualisation genes as a function of reproductive ageing in mice. Development 147, dev185629 (2020).

163. Salim, S., Won, H., Nesbitt-Hawes, E., Campbell, N. \& Abbott, J. Diagnosis and management of endometrial polyps: a critical review of the literature. J. Minim. Invasive Gynecol. 18, 569-581 (2011).

164. Abbott, J. A. Adenomyosis and abnormal uterine bleeding (AUB-A)-pathogenesis, diagnosis, and management. Best. Pract. Res. Clin. Obstet. Gynaecol. 40, 68-81 (2017).

165. Pavone, D., Clemenza, S., Sorbi, F., Fambrini, M. \& Petraglia, F. Epidemiology and risk factors of uterine fibroids. Best. Pract. Res. Clin. Obstet. Gynaecol. 46 3-11 (2018)

166. Lurie, S., Piper, I., Woliovitch, I. \& Glezerman, M. Age-related prevalence of sonographicaly confirmed uterine myomas. J. Obstet. Gynaecol. 25, 42-44 (2005).

167. Selo-Ojeme, D. et al. The incidence of uterine leiomyoma and other pelvic ultrasonographic findings in 2,034 consecutive women in a north London hospital. J. Obstet. Gynaecol. 28, 421-423 (2008).
168. Upson, K., Harmon, Q. E., Laughlin-Tommaso, S. K Umbach, D. M. \& Baird, D. D. Soy-based infant formula feeding and heavy menstrual bleeding among young African American women. Epidemiology 27, 716-725 (2016)

169. Stewart, E. A., Cookson, C. L., Gandolfo, R. A. \& Schulze-Rath, R. Epidemiology of uterine fibroids: a systematic review. BJOG 124, 1501-1512 (2017). A detailed review of the key risk factors related to uterine fibroids, highlighting the importance of race in the epidemiology of fibroids.

170. Jukic, A. M. Z., Upson, K., Harmon, Q. E. \& Baird, D. D. Increasing serum 25 -hydroxyvitamin $D$ is associated with reduced odds of long menstrual cycles in a cross-sectional study of African American women. Fertil. Steril. 106, 172-179.e2 (2016).

171. Parazzini, F. et al. Risk factors for adenomyosis. Hum. Reprod. 12, 1275-1279 (1997).

172. Brodin, P. Immune determinants of COVID-19 disease presentation and severity. Nat. Med. 27, 28-33 (2021).

173. Teuwen, L. A., Geldhof, V., Pasut, A. \& Carmeliet, P. COVID-19: the vasculature unleashed. Nat. Rev. Immunol. 20, 389-391 (2020).

174. Chadchan, S. B., Popli, P., Maurya, V. K. \& Kommagani, R. The SARS-CoV-2 receptor, angiotensin-converting enzyme 2 , is required for human endometrial stromal cell decidualization. Biol. Reprod. 104, 336-343 (2021).

175. Reis, F. M. et al. Angiotensin-(1-7), its receptor Mas, and the angiotensin-converting enzyme type 2 are expressed in the human ovary. Fertil. Steril. 95 176-181 (2011).

176. Thong, E. P., Codner, E., Laven, J. S. E. \& Teede, H. Diabetes: a metabolic and reproductive disorder in women. Lancet Diabetes Endocrinol. 8, 134-149 (2020).

177. Barbieri, R. L., Makris, A. \& Ryan, K. J. Effects of insulin on steroidogenesis in cultured porcine ovarian theca. Fertil. Steril. 40, 237-241 (1983).

178. Hartmann, K. E. et al. Primary Care Management of Abnormal Uterine Bleeding (Agency for Healthcare Research and Quality, 2013).

179. Vannuccini, S., Fondelli, F., Clemenza, S., Galanti, C. $\&$ Petraglia, F. Dysmenorrhea and heavy menstrual bleeding in elite female athletes: quality of life and perceived stress. Reprod. Sci. 27, 888-894 (2020).

180. Bruinvels, G., Burden, R., Brown, N., Richards, T. $\&$ Pedlar, C. The prevalence and impact of heavy menstrual bleeding (menorrhagia) in elite and non-elite athletes. PLOS ONE 11, e0149881 (2016).

181. Pettigrew, R. \& Hamilton-Fairley, D. Obesity and female reproductive function. Br. Med. Bull. 53, 341-358 (1997).

182. Reavey, J. J., Duncan, W. C., Brito-Mutunayagam, S., Reynolds, R. M. \& Critchley, H. O. D. in Obesity and Gynecology 2nd edn Ch. 19 (eds Mahmoud, T. Arulkumaran, S. \& Chervenak, F.) 171-177 (Elsevier, 2020).

183. Seif, M. W., Diamond, K. \& Nickkho-Amiry, M. Obesity and menstrual disorders. Best. Pract. Res. Clin. Obstet. Gynaecol. 29, 516-527 (2015).

184. Royal College of Obstetricians and Gynaecologists/ British Society for Gynaecological Endoscopy. Management of endometrial hyperplasia. Green-top guideline no. 67. https://www.rcog.org.uk/globalassets/ documents/guidelines/green-top-guidelines/gtg_67 endometrial_hyperplasia.pdf (2016)

185. Stoegerer-Hecher, E., Kirchengast, S., Huber, J. C. \& Hartmann, B. Amenorrhea and BMI as independent determinants of patient satisfaction in LNG-IUD users: cross-sectional study in a Central European district. Gynecol. Endocrinol. 28, 119-124 (2012).

186. Klein, D. A., Paradise, S. L. \& Reeder, R. M. Amenorrhea: a systematic approach to diagnosis and management. Am. Fam. Phys. 100, 39-48 (2019).

187. Köpp W et al. Low leptin levels predict amenorrhea in underweight and eating disordered females. Mol. Psychiatry 2, 335-340 (1997)

188. Torstveit, M. \& Sundgot-Borgen, J. Participation in leanness sports but not training volume is associated with menstrual dysfunction: a national survey of 1276 elite athletes and controls. Br. J. Sports Med. 39, 141-147 (2005).

189. Baird, D. D., Dunson, D. B., Hill, M. C., Cousins, D. \& Schectman, J. M. High cumulative incidence of uterine leiomyoma in black and white women: ultrasound evidence. Am. J. Obstet. Gynecol. 188, 100-107 (2003).

190. Yu, O. et al. Adenomyosis incidence, prevalence and treatment: United States population-based study 
2006-2015. Am. J. Obstet. Gynecol. 223, 94.e1-94.e10 (2020).

191. Marsh, E. E. et al. Racial differences in fibroid prevalence and ultrasound findings in asymptomatic young women (18-30 years old): a pilot study. Fertil. Steril. 99, 1951-1957 (2013).

192. Gordley, L. B., Lemasters, G., Simpson, S. R. \& Yiin, J. H. Menstrual disorders and occupational, stress, and racial factors among military personnel. J. Occup. Environ. Med. 42, 871-881 (2000).

193. Blauer, M., Heinonen, P. K., Martikainen, P. M. Tomas, E. \& Ylikomi, T. A novel organotypic culture model for normal human endometrium: regulation of epithelial cell proliferation by estradiol and medroxyprogesterone acetate. Hum. Reprod. 20, 864-871 (2005).

194. Turco, M. Y. et al. Long-term, hormone-responsive organoid cultures of human endometrium in a chemically defined medium. Nat. Cell Biol. 19, 568-577 (2017).

195. Boretto, M. et al. Development of organoids from mouse and human endometrium showing endometrial epithelium physiology and long-term expandability. Development 144, 1775-1786 (2017).

196. Frank, M. L. et al. Importance of transvaginal elastography in the diagnosis of uterine fibroids and adenomyosis. Ultraschall Med. 37, 373-378 (2016).

197. Warren, L. A. et al. Analysis of menstrual effluent: diagnostic potential for endometriosis. Mol. Med. 24, 1 (2018).

198. Xiao, S. et al. A microfluidic culture model of the human reproductive tract and 28-day menstrual cycle. Nat. Commun. 8, 14584 (2017).

199. Thornton, J. Free period products in Scotland. Lancet 396, 1793 (2020).

200. New Zealand Government, Ministry of Education. Access to free period products. https://www.education. govt.nz/our-work/overall-strategies-and-policies/ wellbeing-in-education/access-to-free-period-products (2021).

201. Clark, T. J. \& Stevenson, H. Endometrial polyps and abnormal uterine bleeding (AUB-P): what is the relationship, how are they diagnosed and how are they treated? Best. Pract. Res. Clin. Obstet. Gynaecol. 40, 89-104 (2017).

202. Upson, K. \& Missmer, S. A. Epidemiology of adenomyosis. Semin. Reprod. Med. 38, 89-107 (2020).

203. Chapron, C. et al. Relationship between the magnetic resonance imaging appearance of adenomyosis and endometriosis phenotypes. Hum. Reprod. 32, 1393-1401 (2017).

204. Pinzauti, S. et al. Transvaginal sonographic features of diffuse adenomyosis in 18-30-year-old nulligravid women without endometriosis: association with symptoms. Ultrasound Obstet. Gynecol. 46 730-736 (2015)

205. Critchley, H. O. \& Maybin, J. A. Molecular and cellular causes of abnormal uterine bleeding of endometrial origin Semin Reprod Med 29, 400-409 (2011).

206. Hernandez-Gordillo, V. et al. Fully synthetic matrices for in vitro culture of primary human intestinal enteroids and endometrial organoids. Biomaterials 254, 120125 (2020).

207. Simoni, M. \& Taylor, H. S. Therapeutic strategies involving uterine stem cells in reproductive medicine. Curr. Opin. Obstet. Gynecol. 30, 209-216 (2018).

208. Campo, H. et al. Microphysiological modeling of the human endometrium. Tissue Eng. A 26, 759-768 (2020).

209. van der Molen, R. G. et al. Menstrual blood closely resembles the uterine immune micro-environment and is clearly distinct from peripheral blood. Hum. Reprod. 29, 303-314 (2014).

210. Garcia-Alonso, L. et al. Mapping the temporal and spatial dynamics of the human endometrium in vivo and in vitro. Nat. Genet. 53, 1698-1711 (2021).

211. Jondal, D. E. et al. Uterine fibroids: correlations between MRI appearance and stiffness via magnetic resonance elastography. Abdom. Radiol. 43 , 1456-1463 (2018).

212. Liu, X., Ding, D., Ren, Y. \& Guo, S. W. Transvaginal elastosonography as an imaging technique for diagnosing adenomyosis. Reprod. Sci. 25, 498-514 (2018).
Acknowledgements

The authors acknowledge the support of MRC Centre Grants G1002033 and MR/N022556/1, and MRC Research Grants: G0000066, G0500047, G0600048, MR/J003611/1 and MRC/NIHR 12/206/52 (H.O.D.C.); Wellcome Trust 209589/Z/17/Z, 100646/Z/12/Z, Wellbeing of Women RG 1820 and Academy of Medical Sciences AMS-SGCL13 (J.A.M.); and Wellbeing of Women (RTF902) (V.J.). The authors acknowledge M. Munro (UCLA, Los Angeles, USA), I. Mason (University of Edinburgh) and A. Williams (University of Edinburgh) for their valuable contributions during preparation of the manuscript figures.

\section{Author contributions}

V.J., H.O.D.C., R.R.C. and J.A.M. researched data for article, contributed substantially to discussion of content, wrote the manuscript and reviewed and edited the manuscript before submission.

\section{Competing interests}

H.O.D.C. has received clinical research support for laboratory consumables and staff from Bayer AG, and provides consultancy advice (but with no personal remuneration) to Bayer AG, PregLem SA, Gedeon Richter, Vifor Pharma UK Ltd, AbbVie Inc. and Myovant Sciences $\mathrm{GmbH}$. H.O.D.C. receives royalties from UpToDate for an article on abnormal uterine bleeding. V.J. receives salary and research consumables support from Wellbeing of Women (WoW). R.R.C. has been supported as a clinical research fellow by Bayer AG. J.A.M. receives salary and research consumables support from The Wellcome Trust.

\section{Peer review information}

Nature Reviews Endocrinology thanks C. Gargett, who co-reviewed with F. Cousins; M. Hickey; and L. Salamonsen for their contribution to the peer review of this work.

Publisher's note

Springer Nature remains neutral with regard to jurisdictional claims in published maps and institutional affiliations.

(c) Springer Nature Limited 2022 